\title{
La función de la Comisión Interamericana de Derechos Humanos en el Sistema Interamericano de Derechos Humanos: un repaso a las generalidades básicas que todos debemos conocer
}

\section{The role of the Inter-American Commission on Human Rights in the Inter-American System of Human Rights: a Review of the Basic General Information that Everyone Should Know}

Krúpskaya Ugarte Boluarte* http://dx.doi.org/10.21503/lex.v12i13.36

bogada de la Universidad Nacional San Antonio Abad del Cusco (UNSAAC).

Magíster por la Universidad Carlos III de Madrid, España, con mención en Derechos Fundamentales. ConDiplomadeEstudios Avanzados(DEA) - Doctoradoen Derechos Fundamentales - eneláreadeDerechoInternacionalPúblico, porlaUniversidadCarlos III de Madrid, España. Egresada de la Maestría en Derecho con mención en Política Jurisdiccional delaPontificiaUniversidad Católica del Perú. Diplomaen AltaDirección y Gerencia para el Sector Justicia, por la Escuela de Postgrado de la Universidad del Pacífico. Se desempeña como abogada sénior de la Procuraduría Pública Especializada Supranacional del Ministerio de Justicia y Derechos Humanos. Profesora de maestría en la Universidad Global Educatis (Suiza) y la Universidad Alas Peruanas (Perú). Profesora de pregrado de la Facultad de Derecho y Ciencia Política de la Universidad Alas Peruanas. Correo de contacto: Krupskayaub@hotmail.com.

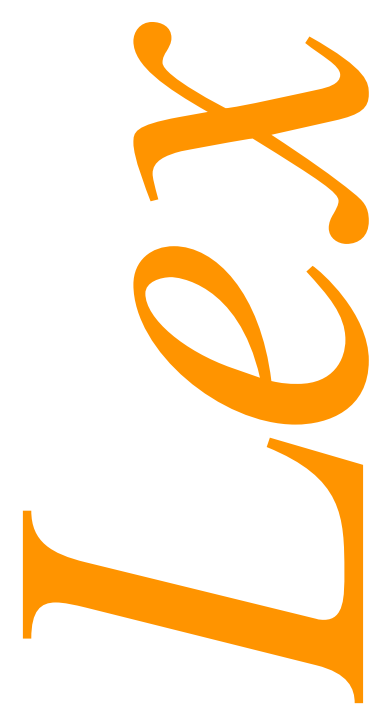




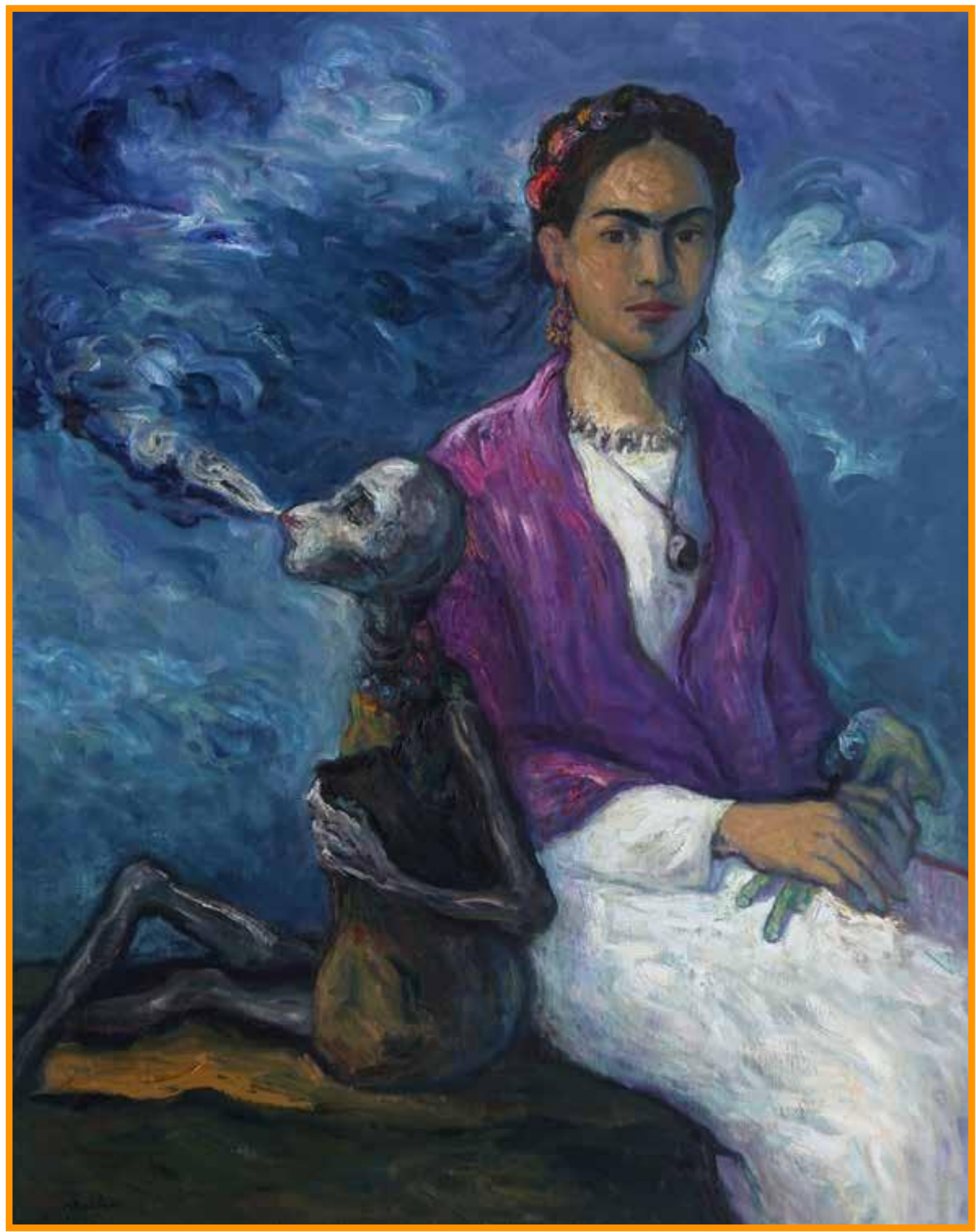

Frida. Óleo sobre tela $(120$ x $90 \mathrm{~cm})$. 


\title{
RESUMEN
}

Se analiza en este artículo la organización y composición de la Comisión Interamericana de Derechos Humanos, en adelante "La Comisión o Comisión IDH". Reconociendo en esta su condición de órgano autónomo de la Organización de los Estados Americanos (OEA), hacemos un repaso de sus funciones principales, como la de promover la defensa de los derechos humanos y la de servir como órgano consultivo de la OEA. Asimismo, se hace un estudio de la representación de la Comisión, de su composición, entre otros aspectos de relevancia. Este trabajo tiene una estructura sencilla orientada al público en general para comprender de manera didáctica la importancia, competencia y funciones de la Comisión Interamericana de Derechos Humanos.

Palabras clave: protección y promoción de los derechos humanos, derechos humanos, derechos fundamentales, competencia, funciones, visitas in loco.

\begin{abstract}
In this article, it is analyzed the organization and composition of the Inter-American Commission on Human Rights hereinafter "Commission o Commission IDH". Recognizing its status in this autonomous organ of the Organization of American States (OAS), we do a review of their main functions, as to promote the defense of human rights and to serve as an advisory body to the OAS. In addition, we do a study of the representation of the Commission, its composition, among other aspects of relevance. This work has a simple structure oriented to the general public to understand the importance of didactic method, jurisdiction, and functions of the Inter-American Commission on Human Rights.
\end{abstract}

Key words: protection and promotion of human rights, human rights, main rights, jurisdiction, functions, visits in situ. 



\section{INTRODUCCIÓN}

La Convención Americana sobre Derechos Humanos está claramente inspirada en la europea, concebida por las democracias libres de Europa Occidental. ${ }^{1}$ Es en el marco de esta influencia que en la IX Conferencia Internacional Americana (Bogotá, 1948), se proclama la denominación de "recomendación" a la Declaración Americana de los Derechos y Deberes del Hombre, sin que se contemple ningún dispositivo para promovero vigilar su observancia. Seguidamente, en 1959, la V Reunión de Consulta de Ministros de Relaciones Exteriores (Santiago, Chile) creó la Comisión Interamericana de Derechos Humanos, cuyo Estatuto fue aprobado en 1960 y reformado por la II Conferencia Interamericana Extraordinaria (Río, 1965), donde se ampliaron los poderes de la Comisión. La III Conferencia Interamericana Extraordinaria (Buenos Aires, 1967) aprobó el Protocolo de Reformas a la Carta de la Organización, que incluyó a la Comisión Interamericana de Derechos Humanos entre los órganos permanentes de esta y que previó la necesidad de adoptar una convención regional especial en materia de derechos humanos, artículos 112 y $150 .^{2}$

Este trabajo parte ubicando a la Comisión Interamericana de Derechos Humanos en el marco de los sistemas de protección y promoción de los derechos humanos que la comunidad internacional reconoce. Se destacan las funciones delaComisión,enespecial la dedeterminar la responsabilidad internacional de los Estados en caso de incurrir en casos de violación de las obligaciones que han contraído en términos de derechos humanos en el marco de la Convención Americana de Derechos Humanos.

En este artículo resaltamos también las atribuciones de la Comisión, desde luego reconociendoquelaComisiónIDHes unórganoregional, estoes, que su coberturageográfica estálimitada a los 35 Estados miembros de la OEA; asimismo, recordamos que respecto a 25

${ }^{1}$ Los trabajos preparatorios muestran cómo ella se origina en proyectos preparados por los gobiernos de Uruguay y de Chile, entonces las más sólidas y arraigadas democracias de América Latina.

${ }^{2}$ Pedro Nikken. "Perfeccionar el sistema interamericano de derechos humanos sin reformar al Pacto de San José". En El futuro del Sistema Interamericano de Protección de los Derechos Humanos, ed., Juan E. Méndez y Francisco Cox, $1^{\text {a }}$. ed. San José: Instituto Interamericano de Derechos Humanos, 1998. pp. 25-41. 
de ellos, la Comisión puede aplicar tanto la Carta de la Organización de Estados Americanos como la Declaración Americana sobre Derechos y Deberes del Hombre, como así también la Convención Americana sobre Derechos Humanos o Pacto de San José de Costa Rica. Ahora, respecto a los diez Estados que todavía no son parte de la Convención Americana de Derechos Humanos, la Comisión IDH pueden de todos modos recibir denuncias y tramitarlas bajo su procedimiento, aplicando a esos casos las normas de la Carta de la OEA y de la Declaración Americana. En ese sentido reafirmamos que la Comisión IDH es uno de los dos órganos de aplicación de la Convención Americana, y esta fue creada en 1959, por Resolución de la Asamblea General de la OEA, y con fines de promoción, desde 1967 está incorporada expresamente a la Carta de la OEA como “órgano principal” de la organización. Se resalta la consecuencia de estas funciones de protección de la Comisión IDH que están otorgadas por los Estados en forma expresa y mediante ratificación con ciertos compromisos internacionales plasmados en tratados, convenios y otros, por lo que las decisiones que adopte gozan de fuerza vinculante para los Estados sometidos a su competencia.

\section{LA EXPANSIÓN DE LOS PODERES DE LA COMISIÓN INTERAMERICANA DE DERECHOS HUMANOS}

Desde el primer momento, la Comisión Interamericana de Derechos Humanos, en adelantela Comisión y/o la Comisión IDH, hizo sentirsu disconformidad con las atribuciones limitadas que se le había concedido, frente a responsabilidad que implicaba la defensa de los derechos humanos. Son estas razones las que llevan a que en su primera sesión de trabajo de fecha 28 de octubre de 1960, el entonces Presidente de la Comisión, Sr. Rómulo Gallegos, al dirigirse al consejo de la OEA, señale "(...) que sus limitados poderes no le permitirían cumplir la misión en defensa de los derechos humanos que los pueblos de América esperaban de ella, y que sentía que sus obligaciones no deberían restringirse a promover el respeto de tales derechos sino velar porque ellos nofueran violados". En ese sentido, propuso modificar el art. 9 del Estatuto y agregar dos artículos adicionales.

\subsection{LAS REFORMAS PROPUESTAS}

AlolargodelaexistenciadelaComisiónIDH, sehanidopresentandoreformasypropuestas decambios. Estas propuestas facultaban ala Comisión para examinar las comunicacionesque le dirigieran individuos o grupos de individuos con relación a serias violaciones de derechos humanos, y le permitían elaborar informes sobre esas comunicaciones y someterlos a los respectivos gobiernos con las recomendaciones que considerara convenientes, y la autorizaban a publicar esos informes en caso de que el gobierno no adoptara las recomendaciones sugeridas. En la Octava Reunión de Consulta de Ministros de Asuntos Exteriores, celebrada en Punta del Este (Uruguay), del 22 al 31 de enero de 1962, se aprobó una Resolución en la que se recomendaba al Consejo de la OEA revisar el Estatuto de la Comisión Interamericana de 
Derechos Humanos, ampliandoy fortaleciendo las atribuciones y facultades de la Comisión, para permitirle promover efectivamente el respeto por los derechos humanos. Sin embargo, entendiendo que el Consejo de la OEA podía continuar indefinidamente con el estudio de las proposiciones formuladas por la Comisión para la reforma de su Estatuto, esta decidió someter el asunto a la II Conferencia Interamericana Extraordinaria, que tuvo lugar en Río de Janeiro del 17 al 30 de noviembre de 1965, y que acogió parcialmente algunas de esas proposiciones.

En este proceso de fortalecimiento se han ido dando otros cambios. Es así que en el año 2011 se modificó el Reglamento de la Comisión Interamericana de Derechos Humanos, aprobado por la Comisión en su $137^{\circ}$ Período Ordinario de Sesiones, celebrado del 28 de octubre al 13 de noviembre de 2009, y modificado el 2 de septiembre de 2011. Durante este período de sesiones, la CIDH decidió: 1) Crear una Relatoría sobre la situación de las defensoras y los defensores de derechos humanos, 2) Darénfasis especial a los derechos de las personas lesbianas, gays, transgénero, bisexualeseintersexuales (LGTBI), y 3) Aprobó un borradorde reforma del Artículo 11 de su Reglamento, el cual se encontraba abierto para la consulta y comentarios de los Estados y de la sociedad civil hasta el 1 de junio de 2011.

\subsection{NATURALEZA Y COMPOSICIÓN}

La Comisión IDH es un órgano autónomo de la Organización de los Estados Americanos. Sus funciones principales son las de promover la observancia y la defensa de los derechos humanos y de servir como órgano consultivo de la Organización en esta materia; ${ }^{3}$ está compuesta por siete miembros, elegidos a título personal por la OEA, quienes deberán ser personas de alta autoridad moral y reconocida versación en materia de derechos humanos. ${ }^{4}$ Representa a todos los Estados miembros de la Organización. ${ }^{5}$ La Directiva de la Comisión IDH estarácompuestapor un Presidente, un primer Vicepresidente, y un segundo Vicepresidente, quienes tendrán las funciones señaladas en este Reglamento. ${ }^{6}$ Los miembros serán elegidos a título personal por la Asamblea de la OEA, de una lista de candidatos propuestos por los gobiernos de los Estados miembros. Cada gobierno puede proponer hasta tres candidatos, ya sea nacionales del Estado que los propone o de cualquier otro Estado miembro de la Organización. Cuando se proponga una terna, por lo menos uno de los candidatos deberá

\footnotetext{
${ }^{3}$ Artículo 1 del Estatuto de la Comisión Interamericana de Derechos Humanos. Aprobado mediante la Resolución $\mathrm{N}^{\circ}$ 447 adoptada por la Asamblea General de la OEA en su noveno período ordinario de sesiones, celebrado en La Paz, Bolivia, en octubre de 1979.

${ }^{4}$ Artículo 1 del Reglamento de la Comisión Interamericana de Derechos Humanos, aprobado por la Comisión en su 137 Período Ordinario de Sesiones, celebrado del 28 de octubre al 13 de noviembre de 2009, y modificado el 2 de septiembre de 2011.

${ }^{5}$ Artículo 2 del Estatuto de la Comisión Interamericana de Derechos Humanos.

${ }^{6}$ Artículo 6 del Reglamento de la CIDH, 2011.
} 
ser nacional de un Estado distinto del proponente. ${ }^{7}$ Seis meses antes de la celebración del período ordinario de sesiones de la Asamblea General de la OEA, previa a la terminación del mandato para el cual fueron elegidos los miembros de la Comisión, el Secretario General de la OEA pedirá por escrito a cada Estado miembro de la Organización que presente sus candidatos dentro de un plazo de noventa días. El Secretario General preparará una lista por orden alfabético de los candidatos presentados y la comunicará a los Estados miembros de la Organización al menos treinta días antes de la próxima Asamblea General. ${ }^{8}$

La Comisión celebrará al menos dos períodos ordinarios de sesiones al año durante el lapso previamente determinado por ella y el número de sesiones extraordinarias que considere necesario. Antes de la finalización del período de sesiones se determinará la fecha y lugar del período de sesiones siguiente. El miembro que, por enfermedad o por cualquier causa grave se viere impedido de asistir a todo o a una parte de cualquier período de sesiones de la Comisión, o para desempeñar cualquier otra función, deberá así notificarlo, tan pronto le sea posible, al Secretario Ejecutivo, quien informará al Presidente y lo hará constar en acta. ${ }^{9}$ Los idiomas oficiales de la Comisión serán el español, el francés, el inglés y el portugués. Los idiomas de trabajo serán los que acuerde la Comisión conforme a los idiomas hablados por sus miembros. Cualquiera de los miembros podrá dispensar la interpretación de debates y la preparación de documentos en su idioma. ${ }^{10} \mathrm{La}$ Comisión, que tiene su sede en Washington D. C, podrá trasladarse y reunirse en el territorio de cualquier Estado americano cuando lo decida por mayoría absoluta de votos y con la anuencia o a invitación del gobierno respectivo. Esta se reunirá en sesiones ordinarias y extraordinarias de conformidad con su Reglamento. ${ }^{11}$

\subsection{FUNCIONES Y ATRIBUCIONES DE LA COMISIÓN INTERAMERICANA DE DERECHOS HUMANOS}

Respecto a los Estados miembros de la Organización de los Estados Americanos, la Comisión tiene las siguientes atribuciones, entre las más importantes: $\left.{ }^{12} 1\right)$ Estimular la conciencia delos derechos humanos en los pueblos de América; 2) Formular recomendaciones a los gobiernos de los Estados para que adopten medidas progresivas en favor de los derechos humanos, dentro del marco de sus legislaciones, de sus preceptos constitucionales y de sus compromisos internacionales, y también disposiciones apropiadas para fomentar el respeto a esos derechos;

${ }^{7}$ Artículo 3 del Estatuto de la Comisión Interamericana de Derechos Humanos.

${ }^{8}$ Artículo 4 del Estatuto de la Comisión Interamericana de Derechos Humanos.

${ }^{9}$ Artículo 14 del Reglamento de la Comisión Interamericana de Derechos Humanos, aprobado por la Comisión en su 137 Período Ordinario de Sesiones, celebrado del 28 de octubre al 13 de noviembre de 2009, y modificado el 2 de septiembre de 2011.

${ }^{10}$ Artículo 22 del Reglamento de la CIDH, 2011.

${ }^{11}$ Artículo 16 del Estatuto de la Comisión Interamericana de Derechos Humanos. Aprobado mediante la Resolución No 447 adoptada por la Asamblea General de la OEA en su noveno Período Ordinario de Sesiones, celebrado en La Paz, Bolivia, octubre de 1979.

${ }^{12}$ Artículo 18 del Estatuto de la Comisión Interamericana de Derechos Humanos. 
3) Preparar los estudios o informes que considere convenientes para el desempeño de sus funciones; 4) Solicitar que los gobiernos de los Estados le proporcionen informes sobre las medidas que adopten en materia de derechos humanos; 5) Presentar al Secretario General el programa-presupuesto de la Comisión para que este lo someta a la Asamblea General.

Entre las atribuciones de que goza el Presidente de la Comisión Interamericana de Derechos Humanosy/oel Vicepresidente están: 1)Convocara sesiones delaComisión, de conformidad con el Estatuto y el Reglamento; 2) Promover los trabajos de la Comisión y velar por el cumplimiento de su programa presupuesto; 3) Rendir un informe escrito a la Comisión, al inicio de sus períodos de sesiones, sobre las actividades desarrolladas durante los recesos en cumplimiento de las funciones que le confieren el Estatuto y el presente Reglamento; 4) Asistir a las reuniones de la Asamblea General de la OEA y a otras actividades relacionadas con la promoción y protección de los derechos humanos; 5) Designar comisiones especiales, comisiones ad hoc y subcomisiones integradas por varios miembros, con el objeto de cumplir cualquier mandato relacionado con su competencia. En relación con los Estados partes en la Convención Americana sobre Derechos Humanos, la Comisión ejercerá sus funciones de conformidad con las atribuciones previstas en la Convención y el Estatuto en su artículo 18, y sus funciones son: ${ }^{13} 1$ ) Diligenciar las peticiones y otras comunicaciones, de conformidad con lo dispuesto en los artículos 44 al 51 de la Convención; 2) Comparecer ante la Corte InteramericanadeDerechosHumanosenlos casos previstosenlaConvención; 3) Solicitarala Corte Interamericana de Derechos Humanos que tome las medidas provisionales que considere pertinentes en asuntos graves y urgentes que aún no estén sometidos a su conocimiento, cuando se haga necesario para evitar daños irreparables a las personas; 4) Consultar a la Corte acerca de la interpretación de la Convención Americana sobre Derechos Humanos o de otros tratados sobre la protección de los derechos humanos en los Estados americanos; 5) Someter a la consideración de la Asamblea General proyectos de protocolos adicionales a la Convención Americana sobre derechos humanos, con el fin de incluir progresivamente en el régimen de protección de la misma otros derechos y libertades; 6) Someter a la Asamblea General, para lo que estime conveniente, por conducto del Secretario General, propuestas de enmienda a la Convención Americana sobre Derechos Humanos.

\subsection{LAS COMUNICACIONES INDIVIDUALES A NIVEL DE LA COMISIÓN INTERAMERICANA DE DERECHOS HUMANOS}

Cualquier persona o grupo de personas, o entidad no gubernamental legalmente reconocida en uno o más Estados miembros de la OEA puede presentar a la Comisión peticiones en su propio nombre o en el de terceras personas, referentes a la presunta violación de alguno de

${ }^{13}$ Artículo 19 del Estatuto de la Comisión Interamericana de Derechos Humanos. Aprobado mediante la Resolución N ${ }^{\circ}$ 447 adoptada por la Asamblea General de la OEA en su noveno Período Ordinario de Sesiones, celebrado en La Paz, Bolivia, en octubre de 1979. 
los derechos humanos reconocidos, según el caso: 1) En la Declaración Americana de los Derechos y Deberes del Hombre; 2) La Convención Americana sobre Derechos Humanos "Pacto de San José de Costa Rica"; 3) El Protocolo Adicional a la Convención Americana sobre Derechos Humanos en Materia de Derechos Económicos, Sociales y Culturales "Protocolo de San Salvador"; 4) El Protocolo a la Convención Americana sobre Derechos Humanos Relativo a la Abolición de la Pena de Muerte; 5)La Convención Interamericana para Prevenir y Sancionar la Tortura; 6) La Convención Interamericana sobre Desaparición Forzada de Personas;7)La Convención Interamericana para Prevenir, Sancionary Erradicar la Violencia contralaMujer"Convención de Belém do Pará”, conformea sus respectivas disposiciones;8) El Estatuto y el Reglamento de la Comisión Interamericana de Derechos Humanos.

El peticionario podrá designar en la propia petición, o en otro escrito, a un abogado u a otra persona para representarlo ante la Comisión. ${ }^{14}$ Asimismo, podrá de motu proprio iniciar la tramitación de una petición que contenga, a su juicio, los requisitos para tal fin. ${ }^{15} \mathrm{El}$ proceso se desarrolla sobre la base de denuncias individuales a partir de violaciones a derechos humanos contemplados enalgunooalgunos delosdistintosinstrumentos regionales (tratados y convenciones interamericanas). Las partes del proceso ante la Comisión son: 1) la persona peticionaria (cualquier persona o grupo de personas; no necesariamente tiene que ser la víctima ni sus familiares, aunque generalmente coinciden), y 2) el Estado o Estados demandados. En situaciones muy especiales — casos graves y urgentes—, la Comisión puede realizar una investigación, previo consentimiento del Estado demandado, tan solo con la presentación de una petición o comunicación que reúna los requisitos formales de admisibilidad (Artículo 48.2 de la Convención Americana de Derechos Humanos).

\subsection{LAS INVESTIGACIONES IN LOCO}

La Comisión IDH podrá realizar una investigación in loco, si lo considera necesario y conveniente, para cuyo eficaz cumplimiento solicitará las facilidades pertinentes, que serán proporcionadas por el Estado en cuestión. En casos graves y urgentes, podrá realizar una investigación in loco previo consentimiento del Estado en cuyo territorio se alegue haberse cometido la violación, tan solo con la presentación de una petición o comunicación que reúna todos los requisitos formales de admisibilidad. Podrá delegar en uno o más de sus miembros la recepción de prueba testimonial conforme a las reglas establecidas en el artículo 65, incisos $5,6,7$ y $8 .{ }^{16}$ En el presente cuadro podemos ver las visitas efectuadas por la Comisión IDH.

${ }^{14}$ Artículo 23 del Reglamento de la Comisión IDH, aprobado por la Comisión en su 137 Período Ordinario de Sesiones, celebrado del 28 de octubre al 13 de noviembre de 2009, y modificado el 2 de septiembre de 2011.

${ }^{15}$ Artículo 24 del Reglamento de la Comisión Interamericana de Derechos Humanos.

${ }^{16}$ Artículo 39 del Reglamento de la Comisión Interamericana de Derechos Humanos, aprobado por la Comisión en su 137 Período Ordinario de Sesiones, celebrado del 28 de octubre al 13 de noviembre de 2009, y modificado el 2 de septiembre de 2011. 


\section{Cuadro 1}

\section{Algunas visitas in loco efectuadas por la Comisión Interamericana de Derechos Humanos hasta mayo de $2003^{17}$}

\begin{tabular}{|c|c|c|c|}
\hline $\mathbf{N}^{\circ}$ & Fecha & Lugar & Observaciones \\
\hline 1 & $22-29$ octubre 1961 & Rep. Dominicana & Primera visita de observación in loco. \\
\hline 2 & 2 enero 1963 & Miami, Florida & Visita a los refugiados cubanos. \\
\hline 3 & $\begin{array}{l}4-7 \text { julio } 1969 \\
8-10 \text { julio } 1969\end{array}$ & $\begin{array}{l}\text { El Salvador } \\
\text { Honduras }\end{array}$ & $\begin{array}{l}\text { Una Comisión Especial permaneció en ambos países hasta el } 25 \text { de } \\
\text { octubre de } 1969 .\end{array}$ \\
\hline 4 & 22 julio - 2 de agosto 1974 & Chile & Visita de observación in loco. \\
\hline 5 & 18 enero 1978 & El Salvador & Segunda visita de observación in loco. \\
\hline 6 & $16-25$ agosto 1978 & Haití & Primera visita de observación in loco. \\
\hline 7 & 3 - 12 octubre 1978 & Nicaragua & Primera visita de observación in loco. \\
\hline 8 & 7 - 9 mayo 1982 & Honduras & Visita al campo de refugiados miskitos en Mocorón. \\
\hline 9 & $28-29$ junio 1982 & $\begin{array}{l}\text { Estados Unidos } \\
\text { Puerto Rico }\end{array}$ & $\begin{array}{l}\text { Visita a centros de detención de refugiados haitianos en Florida y } \\
\text { Puerto Rico. }\end{array}$ \\
\hline 10 & 21 - 26 septiembre 1982 & Estados Unidos & Visita al centro de refugiados haitianos en Brooklyn, Nueva York. \\
\hline 11 & 2 - 8 enero 1983 & México & Visita al campo de refugiados guatemaltecos en Chiapas, México. \\
\hline 12 & $3-7$ enero 1988 & Guyana Francesa & Visita a los campos de refugiados surinameses. \\
\hline 13 & $2-30$ abril 1988 & Nicaragua & Revisión de expedientes de exguardias nacionales (1 834 casos). \\
\hline 14 & 9 -10 marzo 1994 & Guatemala & $\begin{array}{l}\text { Séptima visita a Guatemala para verificar la situación de las } \\
\text { Comunidades de Población en Resistencia (CPR). }\end{array}$ \\
\hline 15 & $3-5$ mayo 1995 & Estados Unidos & $\begin{array}{l}\text { Visita a la Penitenciaría Federal de Lompoc, California, para verificar } \\
\text { las condiciones de detención de los presos "Marielitos" cubanos. }\end{array}$ \\
\hline 16 & 30 mayo 1995 & Estados Unidos & Visita a la Penitenciaría de Leavenworth, Kansas. \\
\hline 17 & 26 abril 1996 & Estados Unidos & $\begin{array}{l}\text { Visita a Allenwood, Pennsylvania, y verificación de las condiciones } \\
\text { carcelarias de los presos "Marielitos". }\end{array}$ \\
\hline 18 & 12 - 18 mayo 1996 & Venezuela & Visita de observación de la situación carcelaria. \\
\hline 19 & 9 - 10 diciembre 1996 & Estados Unidos & $\begin{array}{l}\text { Visita a Marksville y Amite, Louisiana de verificación de las condiciones } \\
\text { carcelarias de los presos "Marielitos". }\end{array}$ \\
\hline 20 & $20-22$ octubre 1997 & Canadá & Visita de observación de las condiciones de los refugiados. \\
\hline
\end{tabular}

\footnotetext{
${ }^{17}$ Información sacada de la página web de la Comisión Interamericana de Derechos Humanos al 2003.
} 


\begin{tabular}{|l|l|l|l|}
\hline 21 & 7 - 9 julio 1998 & Estados Unidos & $\begin{array}{l}\text { Visita a Los Ángelesy San Diego, California, para estudiar la situación } \\
\text { de los trabajadores migrantes y sus familias. }\end{array}$ \\
\hline 22 & 7 -9 julio 1999 & Estados Unidos & Visita a El Paso, Texas. \\
\hline 23 & $11-12$ febrero 2002 & México & $\begin{array}{l}\text { Visita de la Relatoría sobre los Derechos de la Mujer para estudiar la } \\
\text { situación de los derechos de la mujer en Ciudad Juárez.w }\end{array}$ \\
\hline 24 & $18-24$ marzo 2002 & Guatemala & $\begin{array}{l}\text { Visita de la Relatoría sobre los Trabajadores Migratorios y miembros } \\
\text { de sus familias a Guatemala. }\end{array}$ \\
\hline
\end{tabular}

\section{COMPETENCIA DE LA COMISIÓN INTERAMERICANA DE DERECHOS HUMANOS}

\subsection{RATIONE MATERIAE}

La Comisión solo puede conocer de hechos que constituyan una violación a los derechos humanos consagrados en los instrumentos vinculantes del Sistema Interamericano, respecto de aquellos Estados que son parte de la Convención Americana de DH o Convención Americana. Los derechos son aquellos contenidos en dicho tratado y en la Declaración Americana de Derechos y Deberes del Hombre respecto de aquellas materias no contempladas en la Convención Americana. Además, se aplican a los Estados las normas de los protocolos o convenciones de carácter regional de los cuales ellos sean parte. ${ }^{18} \mathrm{La}$ Comisión analiza las peticiones que recibe a la luz de las obligaciones contenidas en los tratados mencionados líneas arriba (en elítem "las comunicaciones individuales a nivel de la Comisión Interamericana de Derechos Humanos). Se entiende, desde luego, que la Comisión tiene competencia para aplicar estos instrumentos en tanto y en cuanto el Estado respectivo los haya ratificado. En este momento, diez de los 35 Estados miembros de la OEA no son parte de la Convención Americana. Naturalmente, estos Estados no son sometidos a la competencia de la Corte Interamericana de Derechos Humanos. Sin embargo, la Comisión tiene competencia para recibir peticiones contra ellos, que analiza a la luz de la Carta de la OEA y de la Declaración Americana. El trámite es esencialmente el mismo que para los casos bajo la Convención Americana. Al pronunciarse la Corte Interamericana de Derechos Humanos o La Corte ${ }^{19}$

${ }^{18}$ Cecilia Medina Quiroga y Claudio Nash Rojas. Sistema Interamericano de Derechos Humanos: introducción a sus mecanismos de protección. Chile: Facultad de Derecho de la Universidad de Chile, 2007, p. 58.

${ }^{19}$ Esta competencia contenciosa de la Corte se remite ratione materiae a la Convención Americana. Es el derecho sustantivo que la Corte aplicará. Para esto hay que recurrir a casos del Art. $5^{\circ}$ de la Convención, que en materia de reservas se estará a lo dispuesto en el Tratado de Viena de Derechos de los Tratados, o al Art. 46.1a). En materia de agotamiento de los recursosinternos, se estará a principios del Derecho Internacional generalmente reconocidos, o Art. 29 de la Convención. En cuanto a las normas de interpretación de la Convención, indica que no podrán interpretarse en sentido que restrinjan o violen normas contenidas en la Declaración Americana de Derechos y Deberes del Hombre (1948). Asimismo, tiene competencia en casos de violaciones de derechos (párrafo a, Art. $8^{\circ}$ y $13^{\circ}$; Protocolo Adicional a la Convención en Derechos Económicos, Sociales y Culturales - Protocolo San Salvador), casos de violaciones y de desaparición forzada 
sobre la fuerza vinculante de la Declaración Americana de Derechos Humanos, que es lo que interesa en este punto, la Corte se refiere a tres elementos que son importantes de destacar:

1) La Corte señala que la Declaración Americana tiene como finalidad dar cabida a la idea protectora de los derechos humanos, que en el Sistema Interamericano es base fundamental deldesarrollodel sistemajurídicointeramericano. ${ }^{20}$ De allíqueel sistema, que seencuentraen constante evolución, deba serinterpretado de acuerdo al contex to dado al momento en que se requiere la interpretación del instrumento en cuestión, siguiendo de esa forma la tesis sobre la interpretación de los documentos internacionales formulada por la Corte Internacional de Justicia. ${ }^{21}$ Por consiguiente, la fuerza legal de la Declaración Americana no puede ser determinada a la luz de lo que los Estados firmantes consideraron en 1948, sino que debe para ello tenerse en cuenta la evolución general del sistema, con lo que enfatiza la idea de la interpretación dinámica.

2. Al analizar la evolución histórica, la Corte pone de manifiesto que los Estados han actuado respecto de la Declaración Americana como si esta fuera un documento obligatorio, que contiene aquellos derechos a los cuales hace referencia la Corte IDH de la OEA; de esta manera, la incorporación de la Declaración al sistema convencional se habría producido por la práctica de los Estados. ${ }^{22}$

3. Para los Estados que no son parte de la Convención Americana, la Declaración es un documento obligatorio a partir de la reforma del artículo 150 de la Carta de la OEA, es decir, es fuente de obligaciones internacionales. ${ }^{23}$ Para aquellos Estados partes de la Convención, también ella tiene fuerza obligatoria de acuerdo a lo preceptuado en el artículo 29 letra d) de dicho tratado, que no puede ser interpretado de forma que implique una liberación de cumplir con los derechos en ella contenidos. ${ }^{24}$ Se puede concluir que, en los casos contra Estados partes de la Convención, la competencia material de la Comisión IDH se encuentra primordialmente en la Convención Americana, pudiendo utilizarse la Declaración Americana para suplir carencias de la Convención Americana. Respecto de los Estados miembros de la OEA que no son parte de la Convención, la norma a aplicar, que es jurídicamente vinculante, es la Declaración Americana de Derechos Humanos y Deberes del Hombre. ${ }^{25}$

de personas. También para aplicar la Convención Interamericana en lo que se refiere a prevenir y sancionar la tortura sí como prevenir, erradicar y sancionar la violencia contra la mujer.

${ }^{20}$ Opinión Consultiva OC-108/89, párr.2.

21 "Un instrumento internacional debe ser interpretado y aplicado en el cuadro del conjunto del sistema jurídico en vigor en el momento en que la interpretación tiene lugar". Legal Consequences for State of the Continued Presence of South África in Namibia - South West África - Notwithstanding Security Council Resolution 276 (1970), Advisory Opinion, I.C.J. Report 1971, p. 16-31.

${ }^{22}$ Ibíd., párr. 42 y 43.

${ }^{23}$ Ibíd. párr., 45.

${ }^{24}$ Ibíd. párr., 46.

${ }^{25}$ Cecilia Medina Quiroga y Claudio Nash Rojas. Op. cit. p. 60. 


\subsection{RATIONE LOCI}

Estacompetenciatiene relación con la norma que disponeque la Comisión Interamericana de Derechos Humanos solo puede conocer de comunicaciones que se refieran a hechos que afectan a personas bajo la jurisdicción del Estado supuestamente responsable de las violaciones a los derechos humanos que se han alegado. ${ }^{26}$ Es el caso por el que Estados Unidos basó su defensa en la incompetencia de la Comisión IDH por ser ella un "órgano consultor" sin facultades para decidir casos, puesto que la Declaración Americana como acuerdo consensuado de una "manifestación acordada de principios generales sobre derechos, no obligatorios". ${ }^{27}$ La Comisión ha sido extremadamente flexible en su interpretación de este concepto, y en dos casos contra Estados Unidos ha extendido el término jurisdicción más allá de lo que ordinariamente se acepta en el Derecho Internacional.

\subsection{RATIONE TEMPORIS}

De acuerdo con el Derecho Internacional, la Convención Americana obliga a los Estados partes desde que la Convención entra en vigencia para cada uno de ellos, y no se aplica a situaciones anteriores a esa fecha ${ }^{28} \mathrm{La}$ Comisión se ha pronunciado en esta materia en forma clara y contundente: "La Comisión no comparte la posible implicación del argumento de inadmisibilidad ratione temporis, según el cual los Estados miembros de la Organización contraen obligaciones de respetar los derechos humanos solo a partir de la ratificación de la Convención. Dicha premisa parecería sugerir que antes de la ratificación de la Convención, los Estados miembros no tenían obligación internacional alguna respecto de los derechos humanos y, concretamente, que está Comisión no tiene competencia para recibir otras denuncias que las del texto Convencional". ${ }^{29}$ Sin perjuicio de ello, en el Sistema Interamericano de protección de los derechos humanos, los Estados no pueden reclamar frente a la Comisión que (...) no existe obligación alguna de respetar y garantizar los derechos humanos antes de la entrada en vigencia de la Convención Americana, ya que todos los Estados miembro de la OEA estaban sujetos, antes de la Convención, y respecto de ciertos derechos hasta ahora, a las normas de la Declaración Americana, y la Comisión es competente para controlar el cumplimiento. ${ }^{30}$

\subsection{RATIONE PERSONAE}

34.1. LEGITIMACIÓN ACTIVA. Los Estados partes de la Convención y la Comisión tienen derecho a presentar un "Caso" ante la Corte Interamericana de Derechos Humanos. También los Estados que participaron en un procedimiento ante la Comisión tienen ese

${ }^{26}$ Ibíd. p. 46.

${ }^{27} \mathrm{CIDH}$, Caso 10573, Informe 31/93 de 14 de octubre de 1993.

${ }^{28}$ Artículo 28 de la Convención de Viena sobre el Derecho de los Tratados, 1969.

${ }^{29}$ CIDH, Caso 9850, Res. 28/92, publicado en el Informe Anual 1990/91, P. 75 Argentina.

${ }^{30}$ Medina Quiroga, Cecilia y Nash Rojas. Op cit. p. 61. 
derecho. La Comisión está facultada para llevar [un Caso] a la Corte Interamericana de Derechos Humanos, conforme se lo atribuye el artículo 57 de la Convención Americana de Derechos Humanos, y por esta razón puede comparecer ante esta. La habilitación a las víctimas para presentar observaciones y comentarios en su caso ha requerido decidir cómo manejar la pluralidad de víctimas en un Caso. En estos casos, las partes deben nombrar un interviniente común. Es decir, en cuanto a la naturaleza de esta disposición, se la ha entendido comounaactio propulari, ${ }^{31}$ toda vezque permite que terceras personas, distintas de la víctima, actúen ante la Comisión activando el procedimiento y llevándolo adelante, sin que sea siquiera necesaria la intervención de la víctima. Asílo ha establecido la propia Comisión: "Quien denuncia un hecho violatorio de los derechos humanos ante la Comisión (...) no requiere la autorización de la víctima" ${ }^{2}$. En ese sentido, la clasificación de las víctimas en directas o potenciales ha servido para enfatizar que el concepto de víctima no requiere que se produzca el daño último, pero, en estricto rigor, hay siempre una afectación directa.

Está posición de la Comisión se refiere a sus facultades dentro del examen de un caso individual; sin embargo, como la Comisión tiene otras facultades, como por ejemplo la del artículo 411.b de la CADH, podría opinar sobre una ley in abstracto haciendo uso de ellas. LaCorte expresa esta idea diciendo: "La Jurisdicción contenciosa de la Corte se ejerce con la finalidad de proteger los derechos y libertades de personas determinadas y no con la de resolver casos abstractos. Noexiste en la Convención disposiciónalgunaquepermitaala Cortedecidir, en el ejercicio de su competencia contenciosa, si una ley que no ha afectado aún los derechos y libertades protegidos de individuos determinados es contraria a la Convención. Como antes se dijo, la Comisión sí podría hacerlo y en esa forma daría cumplimiento a su función principalmente de promover la observancia y defensa de los derechos humanos. También podría hacerlo la Corte en ejercicio de su función consultiva en aplicación del artículo 64.2 de la Convención". ${ }^{33}$ En cuanto a los peticionarios, la Convención ha establecido un requisito en relación con las organizaciones no gubernamentales (ONG): para tener legitimatio ad causam deben estar reconocidas en cualquiera de los Estados Miembros de la OEA, no importando si es o no el Estado denunciado. En el caso de que una petición sea presentada por una ONG que no se encuentre reconocida en ninguno de los Estados Miembros de la organización, pensamos a la luz de lo resuelto por la Corte Interamericana de Derechos Humanos, que esta no puede ser rechazada, sino que debiera admitirse a tramitación bajo la figura de presentación efectuada por un "grupo de personas". La Corte ha tenido oportunidad de

${ }^{31}$ La existencia de un acto propularis no debe confundirse con el hecho de que para que la comunicación sea admisible deba existir a lo menos una víctima, que en el desarrollo jurisprudencial de los órganos de supervisión internacional puede ser directa, cuando la violación final se produjo ya en su contra, o potencial, es decir, cuando una persona corre riesgo de ser afectada directamente por el acto u omisión del cual quiere quejarse.

${ }^{32}$ Comisión IDH, Caso 1954, Res. 59/ 81, publicado en el Informe Anual 1981 / 82, p. 98. Uruguay.

${ }^{33}$ Opiniones Consultivas OC-14/94, párr. 49. 
pronunciarse in extenso sobre este requisito en la Sentencia sobre excepciones preliminares en el caso CastilloPetruzzi,dondeestableció: "Conrespectoaesta excepción, la Cortehacenotar que independientemente del examen que pudiera hacerse, si fuera indispensable, acerca de la existencia y las facultades de FASIC y de las personas que manifiestan actuar en su nombre, es claro que el artículo 44 de la Convención permite que cualquier grupo de personas formule denuncias o quejas por violación de los derechos consagrados por la Convención”. Esta amplia facultad de denunciar es un rasgo característico del sistema de protección internacional de los derechos humanos. En el caso Castillo Petruzzi, este "grupo de personas" (...) satisfacen una de las hipótesis previstas, parafines de legitimación, en el citado artículo 44 de la Convención, como señala: “( ...) la evidente acreditación de esta circunstancia hace innecesario analizar el registro de FASIC y la relación que con dicha fundación guardan o dicen guardar quienes se ostentan como sus representantes".

Esta consideración se fortalece si se recuerda que, como ha manifestado la Corte en otras ocasiones, las formalidades características de ciertas ramas del Derecho Interno no rigen en el Derecho Internacional de los derechos humanos, cuyo principal y determinante cuidado es la debida y completa protección de los derechos humanos. En otras palabras, "la inobservancia de ciertas formalidades no siempre es relevante, pues lo esencial es que se preserven las condiciones necesarias para que los derechos procesales de las partes no sean disminuidos o desequilibrados y paraque se alcancenlos fines paralos cualeshan sidodiseñados los distintos procedimientos". ${ }^{34}$

El sistema de las peticiones individuales permite también la presentación de demandas colectivas. En efecto, en los casos en que la Comisión ha tenido oportunidad de conocer de peticiones colectivas, ha dado curso a su tramitación señalando que estas correspondían a individuos o grupo de personas y, por lo tanto, la petición era admisible. ${ }^{35}$ La Comisión somete a tramitación comunicaciones sobre muchas personas cuya individualización no se ha hecho. Cuando un caso de esta naturaleza llega a conocimiento de la Corte, esta lo ha permitido, siempre que las personas puedan ser individualizadas con posterioridad. ${ }^{36}$ El artículo 45 de la Convención reconoce la competencia de la Comisión para recibir y examinar las comunicaciones en que un Estado alegue que otro Estado parte ha incurrido en violaciones de los derechos humanos establecidos en esta Convención. Paraque la Comisión

${ }^{34}$ Caso Castillo Petruzzi y otros vs. Perú. Excepciones preliminares, párr. 77. En este mismo sentido, se ha pronunciado la Corte Internacional de Justicia, cuando dice que esta "al ejercer una jurisdicción internacional, no está llamada a atribuir a las consideraciones de forma la misma importancia que ellas podrían tener en el Derecho Interno" (Mavrommatis Palestine Concessions, Judgment No. 2, 1924, P.C.I.J., Series A, No. 2, pág. 34; Legal Status of Eastern Greenland, Judgment, 1933, P.C.I.J., Series A/B, No. 53, P.71).

${ }^{35}$ Comisión IDH, Caso 9893, publicado en Informe Anual 1990/91, p. 77. Uruguay.

${ }^{36}$ Ver Caso Penal Miguel Castro Castro vs. Perú, párr. 178. En un sentido contrario, ver Caso Montero Araguren y otros (Retén de Catia) vs. Venezuela, párrs. 29-36. 
pueda conocer estas comunicaciones, es necesaria una declaración de reconocimiento de competencia por parte del Estado, la que puede hacerse para que esta rija por tiempo indefinido, por un período determinado o para casos específicos. Los Estados no habían hecho uso de esa facultad sino hasta el año 2006, cuando el Estado de Nicaragua presentó una denuncia contra el Estado de Costa Rica por las supuestas violaciones de los derechos humanos de dos ciudadanos nicaragüenses en Costa Rica. ${ }^{37}$ Por disposición del Reglamento, la Comisión puede iniciar de motu proprio la "tramitación de una petición que contenga, a su juicio, los requisitos para tal fin". ${ }^{38}$ La norma parece continuar la idea existente desde los comienzos de las actividades de la Comisión, contenida en el artículo 26.2 del Reglamento anterior al modificado el año 2003, pero su nueva redacción intriga, ya que uno se pregunta qué diferencia existe entre una petición que permite iniciar un caso de motu proprio, y las peticiones que dan origen a un caso individual normal. En todo caso, esta disposición parece ser hoy día de escasísima aplicación, en la medida en que las situaciones de violaciones masivas y sistemáticas han disminuido, lo que permite a los afectados presentar peticiones con menor riesgo que antes. ${ }^{39}$

\section{LEGITIMACIÓN PASIVA}

Solo los Estados pertenecientes al Sistema Interamericano pueden ser sujetos pasivos del procedimiento ante la Comisión, que tiene solo respecto de ellos la facultad de examinar su conductaen materia de derechos humanos y asignarles responsabilidad internacional. ${ }^{40}$ Entre los requisitos tenemos:

1. Requisitos formales y materiales de la admisibilidad:

La Secretaría Ejecutiva de la Comisión tendrá la responsabilidad del estudio y tramitación inicial de las peticiones presentadas a la Comisión que llenen todos los requisitos establecidos en el Estatuto y en el artículo 28 del presente Reglamento. Si una petición no reúne los requisitos exigidos en el presente Reglamento, la Secretaría Ejecutiva podrá solicitar al peticionario o a su representante que los complete. Si la Secretaría Ejecutiva tuviera alguna duda sobre el cumplimiento de los requisitos mencionados, consultaráa la Comisión. ${ }^{41}$ La Comisión constituirá un grupo detrabajo compuestoportres o más de sus miembros afin de estudiar, entre sesiones, la admisibilidad de las

${ }^{37}$ CIDH. Caso Interestatal 01/06, Informe N ${ }^{\circ}$ 11/07, Inadmisible, Nicaragua c. Costa Rica. OEA/ Ser/L/V/II.127. Consultado en http://www.cidh.org.

${ }^{38}$ Artículo 24 del Reglamento de la Comisión Interamericana de Derechos Humanos, aprobado por la Comisión en su 137 Período Ordinario de Sesiones, celebrado del 28 de octubre al 13 de noviembre de 2009, y modificado el 2 de septiembre de 2011.

${ }^{39}$ Medina Quiroga, Cecilia y Nash Rojas. Op cit. p. 58.

${ }^{40}$ Ibíd.

${ }^{41}$ Artículo 26 del Reglamento de la Comisión Interamericana de Derechos Humanos, aprobado por la Comisión en su 137 Período Ordinario de Sesiones, celebrado del 28 de octubre al 13 de noviembre de 2009, y modificado el 2 de septiembre de 2011. 
peticiones y formular recomendaciones al pleno. ${ }^{42}$ Una vez consideradas las posiciones de las partes, la Comisión se pronunciará sobre la admisibilidad del asunto. ${ }^{43}$ La apertura del caso se efectuará mediante una comunicación escrita a ambas partes. Cuando la Comisión proceda de conformidad con el artículo 30 inciso 7 del presente Reglamento, abrirá un caso e informará a las partes por escrito que ha diferido el tratamiento de la admisibilidad hasta el debate y decisión sobre el fondo ${ }^{44}$

2. LaCompetencia (...) al igual que en el Derecho Interno, (...) tiene varias dimensiones que se precisan con signos más definitorios, para entenderlas: ${ }^{45}$

1) La competencia por razón de la materia significa que la comunicación debe invocar la violación de un derecho contemplado en la Convención o en otro instrumento sobre el cual la CIDH tenga atribuciones de adjudicación de controversias; 2) La competencia por razón de la persona, la denuncia debe referirse a un Estado parte en esos instrumentos, y la víctima presunta debe ser una persona sujeta a la jurisdicción de ese Estado;3) La competencia ratione loci significa que los hechos denunciados deben haber ocurrido en un sitio sujeto a la jurisdicción del Estado; y 4) La competencia ratione temporis alude a que esos hechos deben haber ocurrido durante la vigencia efectiva del instrumento cuya violación se alega.

3. El previo agotamiento de los recursos contemplados en el Derecho Interno del país respectivo $^{46}$. Debe presentarse la petición en los 6 meses siguientes al agotamiento de los

${ }^{42}$ Artículo 35 del Reglamento de la Comisión Interamericana de Derechos Humanos.

${ }^{43}$ Los informes de admisibilidad e inadmisibilidad serán públicos y la Comisión los incluirá en su Informe Anual a la Asamblea General de la OEA. Con ocasión de la adopción del Informe de Admisibilidad, la petición será registrada como "Caso" y se iniciará el procedimiento sobre el fondo. La adopción del Informe de Admisibilidad no prejuzga sobre el fondo del asunto. En circunstancias excepcionales, y luego de haber solicitado información a las partes de acuerdo a lo dispuesto en el artículo 30 del presente Reglamento, la Comisión podrá abrir el caso pero diferir el tratamiento de la admisibilidad hasta el debate y decisión sobre el fondo.

${ }^{44}$ Artículo 36 del Reglamento de la Comisión Interamericana de Derechos Humanos.

${ }^{45}$ Conferencia dictada en el XX Curso Interdisciplinario en Derechos Humanos, San José de Costa Rica, 24 de julio de 2002, IIDH. Jurista argentino, Director del Center for Civil and Human Rights de la Escuela de Derecho de la Universidad de Notre Dame. Ex-Presidente de la Comisión Interamericana de Derechos Humanos; Miembro de la Asamblea General y Ex-Director Ejecutivo del IIDH; Ex-Director Ejecutivo de American Watch.

${ }^{46}$ La Comisión, en atención al artículo 30 del Reglamento vigente de la CIDH, a través de su Secretaría Ejecutiva, dará trámite a las peticiones que reúnan los requisitos previstos en el artículo 28 del Reglamento de la CIDH. En los casos en los cuales resulten aplicables las excepciones al requisito del previo agotamiento de los recursos internos, la petición deberá presentarse dentro de un plazo razonable, a criterio de la Comisión. La Comisión considerará la fecha en que haya ocurrido la presunta violación de los derechos y las circunstancias de cada caso. Esta condición refleja el carácter eminentemente subsidiario de los sistemas internacionales de protección. Además, su fundamento es tanto la necesidad de que el Estado conozca con anticipación el asunto sometido al sistema internacional, como la oportunidad de remediar la situación violatoria de un derecho en tiempo y forma. Aunque este es un requisito importante, los sistemas prevén excepciones al agotamiento, en caso de inexistencia de un recurso idóneo en el Derecho Interno; de demora injustificada en su trámite; y de existencia de un patrón sistemático de negación del recurso que lo haga superfluo en la práctica. Con el fin de decidir sobre la admisibilidad del asunto, la Comisión verificará si se han interpuesto y agotado los recursos de la jurisdicción interna, conforme a los principios del Derecho Internacional generalmente reconocidos. Las disposiciones del párrafo precedente no se aplicarán cuando no exista en la legislación interna del Estado en cuestión el debido proceso legal para la protección del derecho o derechos que se alegan han sido violados, no se haya permitido al presunto 
recursos internos, amenos que se demuestre que sellevaron acabolas gestiones para agotarlos y ello no fue posible. En tal caso, de todos modos la denuncia debe ser presentada en un plazo prudencial desde la última actividad en Derecho Interno. La Comisión tomará en consideración las peticiones sobre presuntas violaciones de los derechos humanos consagrados en la Convención Americana sobre Derechos Humanos y otros instrumentos aplicables, con relación a los Estados miembros de la OEA, solamente cuando llenen los requisitos establecidos en tales instrumentos, en el Estatuto y en el presente Reglamento. ${ }^{47}$ Las peticiones dirigidas a la Comisión deberán contener la siguiente información, según el artículo 28 del reglamento vigente de la $\mathrm{CIDH}$. Además, la petición debe consignar la siguiente información:

1) El nombre, nacionalidad y firma de la persona o personas denunciadas o, en el caso de que el peticionario sea una entidad no gubernamental, el nombre y la firma de su representante o representantes legales; 2) Solicitud de que la identidad del peticionario se mantenga en reserva frente al Estado, si asílo requiere el peticionario; 3) Domicilio o dirección para recibir correspondencia de la Comisión; 4) Narración de los hechos, especificando lugar y fecha de las violaciones alegadas; 5) Nombre de la presunta víctima; 6) Indicación del Estado que el peticionario considera responsable de la violación de alguno de los derechos humanos consagrados en la Convención Americana sobre Derechos Humanos y otros instrumentos aplicables, aunque no se haga una referencia específica al artículo presuntamente violado; y 7) Indicar si el caso fue sometido a otro mecanismo o procedimiento de solución de controversia.

4. La Secretaría Ejecutiva de la Comisión tendrá la responsabilidad del estudio y tramitación inicial de las peticiones presentadas a la Comisión que llenen todos los requisitos establecidos en el Estatuto y en el artículo 28 del presente Reglamento. Si una petición no reúne los requisitos exigidos en el presente Reglamento, la Secretaría Ejecutiva podrá solicitar al peticionario o a su representante que los complete. Si la Secretaría Ejecutiva tuviera alguna duda sobre el cumplimiento de los requisitos mencionados, consultará a la Comisión. ${ }^{48} \mathrm{Si}$ falta alguno de estos requisitos, la Secretaría Ejecutiva asiste a los interesados en completar la petición. Con el traslado al Estado comienza el trámite de la primera etapa, llamada de admisibilidad. En ella, el Estado puede oponer objeciones al tratamiento del asunto, sobre la base de la presunta ausencia de alguno de los requisitos de competencia de la Comisión o de

lesionado en sus derechos el acceso a los recursos de la jurisdicción interna, o haya sido impedido de agotarlos, o haya retardo injustificado en la decisión sobre los mencionados recursos. Cuando el peticionario alegue la imposibilidad de comprobar el cumplimiento del requisito señalado en este artículo, corresponderá al Estado en cuestión demostrar que los recursos internos no han sido agotados, a menos que ello se deduzca claramente del expediente.

${ }^{47}$ Artículo 27 del Reglamento de la Comisión Interamericana de Derechos Humanos, aprobado por la Comisión en su 137 Período Ordinario de Sesiones, celebrado del 28 de octubre al 13 de noviembre de 2009, y modificado el 2 de septiembre de 2011.

${ }^{48}$ Artículo 26 del Reglamento de la Comisión Interamericana de Derechos Humanos, aprobado por la Comisión en su 137 Período Ordinario de Sesiones, celebrado del 28 de octubre al 13 de noviembre de 2009, y modificado el 2 de septiembre de 2011. 
admisibilidad del caso. Se produce así un intercambio de escritos y documentación entre las partes, hasta que la Comisión está en condiciones de decidir. En ocasiones se fijan audiencias para discutir la admisibilidad.

5. La Comisión emite un Informe de Admisibilidad, y si acoge la denuncia se abre la etapa de discusión del fondo del asunto. En el mismo acto, la Comisión se pone a disposición de las partes para alcanzar una solución amistosa. También se suelen celebrar audiencias de solución amistosa. Si no hay proceso de solución amistosa, o si el mismo fracasa, se recaban medios de prueba de las partes, y en ocasiones se reciben testimonios en audiencia oral. En general, sin embargo, las audiencias en esta segunda etapa son para la presentación oral de argumentos de hecho y de derecho. Al concluir el debate, la Comisión dicta un Informe en base al artículo 50 de la Convención Americana de Derechos Humanos, en el que decide si los hechos configuran violación a alguna norma de la Convención o de otros instrumentos. En caso afirmativo, también incluye recomendaciones sobre medidas a adoptar por el Estado para remediar la violación. Este informe se entrega al Estado, y se notifica al peticionario sobre su emisión. El contenido del informe es confidencial para los países que han aceptado la competencia de la Corte Interamericana de Derechos Humanos.

6. De acuerdo con la Convención, la Comisión tiene discreción absoluta para decidir. Si envía el caso a la Corte Interamericana de Derechos Humanos o no y si el caso no puede ir a la Corte por falta de competencia, en esa situación, la Comisión emite un segundo informe en base al artículo 51 de la Convención Americana de Derechos Humanos, que es definitivo. En un acto posterior resuelve asimismo su publicación. Conforme a la práctica actual de la Comisión, y a las últimas reformas a su reglamento, se puede afirmar que: 1) En principio todos los casos que pueden ir a la Corte se remiten, a menos que la CIDH decidalo contrario sobre la base de criterios establecidos en el Reglamento; 2) Si se emite un informe del Art. 51 en lugarde enviar el caso a la Corte, esta decisión invariablemente se publica.

\section{LA CARGA DE LA PRUEBA A NIVEL DE LA COMISIÓN INTERAMERICANA DE DERECHOS HUMANOS}

Durante la audiencia, las partes podrán presentar cualquier documento, testimonio, informe pericial o elemento de prueba, a petición de parte o de oficio, la Comisión podrá recibir el testimonio de testigos o peritos. Con relación a las pruebas documentales presentadas durante la audiencia, la Comisión otorgará a las partes un plazo prudencial para que presenten sus observaciones. La parte que proponga testigos o peritos para una audiencia deberá manifestarlo en su solicitud, identificando al testigo o perito y el objeto de su testimonio o peritaje. Al decidir sobre la solicitud de audiencia, la Comisión determinará asimismo la recepción de la prueba testimonial o pericial propuesta. 
El ofrecimiento de los testimonios y pericias por una de las partes será notificado a la otra parte por la Comisión Interamericana de Derechos Humanos. En circunstancias extraordinarias, a criterio de la Comisión, con el fin de salvaguardar la prueba, podrá recibir testimonios en las audiencias, sin sujeción a lo dispuesto en el párrafo anterior. En tales circunstancias, tomará las medidas necesarias para garantizar el equilibrio procesal de las partes en el asunto sometido a su consideración. Es el caso en que la Comisión oirá a un testigo a la vez, y los restantes permanecerán fuera de la sala; asimismo, los testigos no podrán leer sus presentaciones ante la Comisión. Antes de su intervención, los testigos y peritos deberán identificarse y prestar juramento o promesa solemne de decir la verdad. A solicitud expresa delinteresado, la Comisión podrámanteneren reservalaidentidad del testigooperito cuando sea necesario para proteger a estos o a otras personas. ${ }^{49} \mathrm{Cuando}$ existe ausencia de litis pendencia, la Comisión declarará inadmisible cualquier petición o caso cuando: ${ }^{50} 1$ ) No exponga hechos que caractericen una violación de los derechos a que se refiere el artículo 27 del presente Reglamento;2)Seamanifiestamenteinfundadaoimprocedente, según resulte de la exposición del propio peticionario o del Estado; o 3) La inadmisibilidad o improcedencia resulten de una información o prueba sobreviniente presentada a la Comisión.

En caso de desistimiento o archivo de peticiones o casos, el peticionario podrá desistir en cualquier momento de su petición o caso, a cuyo efecto deberá manifestarlo por escrito a la Comisión. La manifestación del peticionario será analizada por la Comisión, que podrá archivar la petición o caso si lo estima procedente, o podrá proseguir el trámite en interés de proteger un derecho determinado.$^{51}$ En cualquier momento del procedimiento, la Comisión podrá decidir sobre el archivo del expediente cuando: 1) verifique que no existen o subsisten los motivos de la petición o caso; o 2) no se cuente con la información necesaria para alcanzar una decisión sobre la petición o caso. Antes de considerar el archivo de una petición o caso, se solicitará a los peticionarios que presenten la información necesaria y se les notificará la posibilidad de una decisión de archivo. Una vezexpirado el plazo establecido para la presentación de dicha información, la Comisión procederá a adoptar la decisión correspondiente..$^{52}$

${ }^{49}$ Artículo 65 del Reglamento de la Comisión Interamericana de Derechos Humanos, aprobado por la Comisión en su 137 Período ordinario de Sesiones, celebrado del 28 de octubre al 13 de noviembre de 2009, y modificado el 2 de septiembre de 2011.

${ }^{50}$ Artículo 34 del Reglamento de la Comisión Interamericana de Derechos Humanos.

${ }^{51}$ Artículo 41 del Reglamento de la Comisión Interamericana de Derechos Humanos.

${ }^{52}$ Artículo 42 del Reglamento de la Comisión Interamericana de Derechos Humanos. 


\section{EL PROCEDIMIENTO ANTE LA COMISIÓN INTERAMERICANA DE DERECHOS HUMANOS Y LOS ARTÍCULOS 50 Y 51 DE LA CONVENCIÓN AMERICANA DE DERECHOS HUMANOS}

En los sistemas de protección internacional de los derechos humanos, el órgano de supervisión tiene facultades para dirigir el proceso, algunas de las cuales son discrecionales, en tanto esas atribuciones - y especialmente la modalidad de su ejercicio- pueden afectar garantías procesales del Estado demandado, lo que influye inevitablemente en el grado de voluntad de los Estados de ratificar un instrumento internacional de protección de los derechos humanos. De allí la importancia de analizar la práctica de los dos órganos cuando dirigen y ordenan un proceso que inevitablemente tiene amplio margen para la flexibilidad procesal y para la improvisación. ${ }^{53}$ En el caso del procedimiento contencioso contemplado en la Convención Americana de Derechos Humanos, y en particular durante la etapa del proceso en la cual un caso es sometido a dicha jurisdicción regional por la Comisión Interamericana de Derechos Humanos,${ }^{54}$ el estudio de la práctica de la Comisión y de la jurisprudencia de la Corte señala en forma enfática, entre otros aspectos, que: 1) Las reglas relativas al plazo de tres meses que tiene la Comisión para someter un caso a la Corte han dado lugar a interpretaciones divergentes de parte de cada órgano; 2) No existencriterios técnico-jurídicos de la Comisión para, después de elaborar su informe del Artículo 50 de la Convención, decidir si ha de someter o no un caso a la Corte; 3 ) La voluntad de la parte peticionaria de lograr que su caso llegue a conocimiento de la Corte no parece jugar papel alguno en la determinación que adopte la Comisión. Sin embargo, en un caso reciente en que la peticionaria manifestó su voluntad de que su caso no fuera remitido, la Comisión respetó ese criterio; 4) El Estado que se agravie de un informe desfavorable de la Comisión emitido bajo el Artículo 50 podrá siempre remitir el caso a la Corte. ${ }^{55} \mathrm{El}$ procedimiento ordinario de peticiones o comunicaciones individuales consiste, fundamentalmente, en cinco etapas bien determinadas en los artículos 48 a 51 de la Convención Americana, ${ }^{56}$ como podemos

${ }^{53}$ Juan E. Méndez. "Una aproximación crítica a la interpretación vigente de los artículos 50 y 59 de la Convención”. En: El Futuro del Sistema Interamericano de Protección de los Derechos Humanos, ed. Juan E. Méndez y Francisco Cox, $1^{\mathrm{a}}$. ed. San José: Instituto Interamericano de Derechos Humanos, 1998, p. 242.

${ }^{54}$ Opinión Consultiva OC-13, párr. 50. La Corte ha dicho: "Está decisión de la Comisión de si somete al caso a la Corte o no no es discrecional, sino que debe apoyarse en la alternativa que sea más favorable para la tutela de los derechos establecidos en la Convención (...)".

${ }^{55}$ Informe $\mathrm{N}^{\circ} 31 / 96$ en Comisión Interamericana de Derechos Humanos, Informe anual de la Comisión Interamericana de Derechos Humanos 1996, Washington D.C., p. 425 y siguientes (Caso de Diana Ortiz).

${ }^{56}$ Estas son: 1) La de admisibilidad es una de las más importantes porque refleja el sistema más amplio de protección que existe, ya que no es requisito que la persona peticionaria deba ser víctima o familiar de la víctima como se exige en todos los sistemas de quejas individuales internacionales, sino que la petición la puede plantear cualquier persona o grupo de personas (Artículo 44 de la Convención Americana). Claro está, como en todos los casos individuales, es un requisito sine qua non agotar primero los recursos de la jurisdicción interna, es decir, aquellos que sean eficaces y expeditos en los términos del artículo 25 de la Convención Americana (aquel recurso sencillo y rápido que ampare contra actos que violen derechos fundamentales reconocidos en la Constitución, la Ley o la Convención Americana, es decir, el recurso 


\section{observarenel esquemaelaboradoenla Conferenciadictadaen el XX CursoInterdisciplinario en Derechos Humanos, San José de Costa Rica, 24 de julio de 2002.}

\section{Cuadro 2}

\section{Fase Comisión Interamericana de Derechos Humanos}

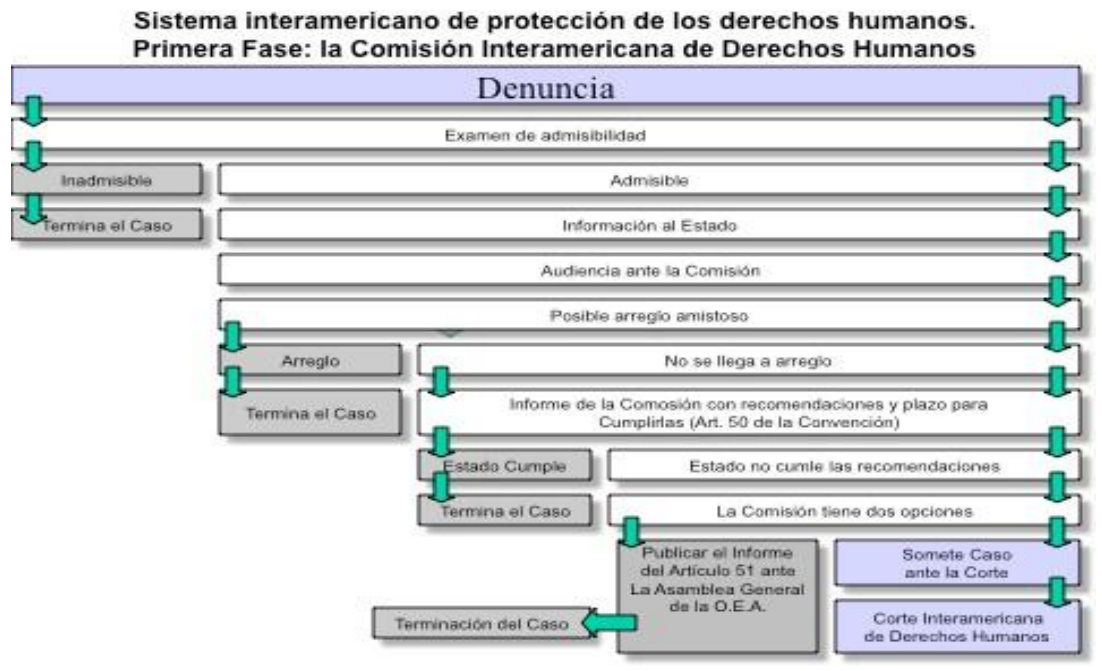

de amparo, hábeas corpus o hábeas data, según sea el caso). Cabe indicar que no en todos los casos deben agotarse los recursos internos. En situaciones muy especiales, puede obviarse ese requisito; a saber: a. Cuando no exista en la legislación interna el debido proceso legal para la protección del derecho o derechos que se alega han sido violados; $b$. Cuando no se haya permitido al presunto lesionado en sus derechos el acceso a los recursos de la jurisdicción interna, o haya sido impedido de agotarlos; c. Cuando haya retardo injustificado en la decisión sobre los recursos mencionados; d. Cuando existiere un temor generalizado en el Estado demandado para plantear casos de derechos humanos por parte de abogados defensores en esa materia; e. Cuando no hubiere asistencia letrada gratuita en materia penal. 2) Los otros dos requisitos de admisibilidad son: que una vez agotados los recursos internos, la persona peticionaria debe presentar la denuncia dentro de los seis meses siguientes a su agotamiento y que la materia objeto de la petición o comunicación no esté pendiente de otro procedimiento de arreglo internacional (litis pendencia). 3) Una vez que la Comisión hace un estudio de admisibilidad, emite un informe de admisibilidad o de inadmisibilidad, según sea la situación. 4) Si se declara la admisibilidad, la Comisión se puede poner a disposición de las partes para que puedan discutir la posibilidad de llegar a una solución amistosa (Artículo 48.1.f. Convención Americana), posibilidad que puede ser planteada en cualquier etapa del proceso ante la Comisión, pero la misma debe vigilar porque el eventual arreglo amistoso sea acorde con el respeto a los derechos humanos contenidos en la Convención Americana. 5) Una vez declarada la admisibilidad y habiendo recibido informaciones del Estado demandado y de la parte peticionaria, la Comisión inicia la etapa de investigación de los hechos mediante un examen del asunto planteado, para cuyos efectos, todas las partes tendrán conocimiento de las actuaciones procesales, las cuales le proporcionarán todas las facilidades necesarias. 6) La Comisión puede, incluso, solicitarles a las partes cualquier información pertinente y recibir escritos y exposiciones verbales; en este último caso, mediante el señalamiento de una audiencia privada junto con las partes. 7) Finalizada la etapa de investigación y de no haberse llegado a una solución amistosa, la Comisión emite el Informe del artículo 50 de la Convención Americana, en el que expone los hechos, sus conclusiones y recomendaciones, para lo cual le otorga al Estado demandado un plazo para cumplirlas que nunca podrá ser mayor de tres meses. 
El Informe es transmitido a los Estados interesados, los cuales no pueden publicarlo. Dentro de ese plazo de tres meses, si el Estado no acata sus recomendaciones, la Comisión puede tomar las siguientes decisiones: 1) Enviar el caso a la Corte Interamericana, lo cual no es automático: primero pide el parecer del peticionario, que además debe incluir la posición de la víctima o sus familiares si fueran distintos del peticionario, argumentación que debe ser presentada dentro del mes de su notificación. Luego, la Comisión considerará esa posición del peticionario, más los siguientes aspectos: a) La naturaleza y gravedad de la violación; b) La necesidad de desarrollar o aclarar la jurisprudencia del sistema; c) El eventual efecto de la decisión en los ordenamientos jurídicos de los Estados miembros y la calidad de la prueba disponible. En caso de no enviar el caso a la Corte, emite, por mayoría absoluta de votos, el Informe en base al artículo 51 de la Convención Americana de Derechos Humanos, con su opinión y conclusiones finales y recomendaciones. Este informe será transmitido a las partes, las cuales, en el plazo fijado por la Comisión Interamericana de Derechos Humanos, informarán sobre el cumplimiento de las recomendaciones, evaluando el cumplimiento delas mismas. La Comisión decide si publica ese informe, ya sea incluyéndoloen su Informe Anual a la Asamblea General de la OEA o publicándolo en cualquier otro medio que considere apropiado. Podemos observar el esquema de procedimiento en el siguiente cuadro.

Cuadro 3

Sistema Interamericano de Derechos Humanos Esquemas de Procedimiento

Etapas de una denuncia por violación de derechos humanos presentada ante la Comisión Interamericana de Derechos Humanos ${ }^{1}$

1. Denuncia ante la Comisión.

2. Evaluación de cuestiones de admisión.

3. Evaluación de fondo.

4. Vías de solución.

4.1. Solución amistosa.

4.2. Sistema de informe.

4.3. Remisión del asunto a la Corte.

Puede pedir medidas provisionales a la Corte en cualquier etapa del proceso, o puede dictar medidas cautelares. 
Etapas de un asunto sometido a la Corte Interamericana de Derechos Humanos

C del punto 4.3 del esquema anterior)

1. Presentación del asunto ante la Corte.

2. Evaluación de cuestiones de admisión.

3. Evaluación de fondo.

4. Resolución: dictado de sentencia.

4.1. El Estado no es condenado por no ser responsable de la violación. Por lo tanto, no hay responsabilidad internacional del Estado.

4.2. El Estado es condenado por ser responsable de violación(es) a los derechos humanos $\rightarrow$ Obligación de reparar a cargo del Estado condenado.

Puede disponer medidas provisionales en cualquier etapa del proceso.

\section{LAS MEDIDAS CAUTELARES}

En situaciones de gravedad y urgencia, la Comisión podrá, a iniciativa propia o a solicitud de parte, solicitar que un Estado adopte medidas cautelares para prevenir daños irreparables a las personas o al objeto del proceso en conexión con una petición o caso pendiente y/o a personas que se encuentren bajo la jurisdicción de este, en forma independiente de cualquier petición o caso pendiente. ${ }^{57}$ Las medidas a las que se refieren los incisos 1 y 2 anteriores podrán ser de naturaleza colectiva a fin de prevenir un daño irreparable a las personas debido a su vínculo con una organización, grupo o comunidad de personas determinadas o determinables. La Comisión considerará la gravedad y urgencia de la situación, su contexto y la inminencia del daño en cuestión al decidir sobre si corresponde solicitar a un Estado la adopción de medidas cautelares.

La Comisión también tendrá en cuenta: 1) Si se ha denunciado la situación de riesgo ante las autoridades pertinentes o los motivos por los cuales no hubiera podido hacerse; 2) La identificación individual de los potenciales beneficiarios de las medidas cautelares o la determinación del grupo al que pertenecen; y 3) La expresa conformidad de los potenciales beneficiarios cuando la solicitud sea presentada a la Comisión por un tercero, salvo en situaciones en las que la ausencia de consentimiento se encuentre justificada. La Comisión podrá requerir a las partes interesadas información relevante sobre cualquier

${ }^{57}$ Artículo 25 del Reglamento de la Comisión Interamericana de Derechos Humanos, aprobado por la Comisión en su 137 Período ordinario de Sesiones, celebrado del 28 de octubre al 13 de noviembre de 2009, y modificado el 2 de septiembre de 2011. 
asunto relacionado con el otorgamiento, observancia y vigencia de las medidas cautelares, respecto al incumplimiento sustancial de los beneficiarios o sus representantes. Con estos requerimientos, podrá ser considerado como causal para que la Comisión deje sin efecto la solicitud al Estado de adoptar medidas cautelares. En caso de medidas cautelares de naturaleza colectiva, la Comisión podrá establecer otros mecanismos apropiados para su seguimiento y revisión periódica. El otorgamiento de esas medidas y su adopción por el Estado no constituirán prejuzgamiento sobre la violación de los derechos protegidos en la Convención Americana sobre Derechos Humanos y otros instrumentos aplicables. La Comisión podrá solicitar a la Corte la adopción de medidas provisionales en casos de extrema gravedad y urgencia, y cuando se haga necesario para evitar un daño irreparable a las personas, en un asunto no sometido aún a consideración de la Corte. Cuando la Comisión no se encontrare reunida, dicha solicitud podrá hacerla el Presidente o, en ausencia de este, uno de los Vicepresidentes, por su orden. ${ }^{58}$

\section{LA SOLUCIÓN AMISTOSA}

La solución amistosa como método de resolución de conflictos existe desde la creación de la Convención Americana, aunque sus beneficios comenzaron a ser utilizados por los usuarios del sistema recién en la década del noventa. La propia Comisión Interamericana y la Corte fueron reticentes a su utilización, considerando que no todos los casos son susceptibles de solución por vía de la negociación. Inclusive los comisionados al redactar su reglamento compartieronestaopiniónal expresar, en suartículo40, “que, ajuiciodelaComisión, elasunto por su naturaleza sea susceptible de solucionarse mediante la utilización del procedimiento de solución amistosa". Ello constituye un poder discrecional para la Comisión, que la faculta para decidir qué casos son susceptibles de solución amistosa, de acuerdo a la naturaleza de los derechos que se alegan violados. Es importante tener en cuenta que la solución amistosa, como procedimiento, es beneficiosa tanto para las partes como para el propio Sistema Interamericano, cualquiera fuese la instancia en que este se active.

\subsection{PROCEDIMIENTO NOVEDOSO A NIVEL DEL SISTEMA REGIONAL DE PROTECCIÓN DE LOS DERECHOS HUMANOS}

En nuestro Sistema Regional de Protección de los Derechos Humanos, la solución amistosa es un procedimiento novedoso que fue inspirado en el europeo, que prevé el arreglo amistoso. Este dispone que en caso de que se estime admisible la demanda, "se pondrá a disposición de los interesados, a fin de llegar a un arreglo amistoso del asunto que se inspire en el respeto a los derechos humanos tal como lo reconoce el presente convenio. En el Pacto

${ }^{58}$ Artículo 76 del Reglamento de la Comisión Interamericana de Derechos Humanos, aprobado por la Comisión en su 137 Período Ordinario de Sesiones, celebrado del 28 de octubre al 13 de noviembre de 2009, y modificado el 2 de septiembre de 2011. 
de San José de Costa Rica o Convención Americana [...], la posibilidad de poner fin a un conflicto por vía de la negociación está contemplada en los siguientes artículos: en la Sección 4 relativa al Procedimiento, artículos $48,{ }^{59} 49,{ }^{60}$ y $50 .{ }^{61}$ En el reglamento de la Comisión, artículo $40,{ }^{62}$ aprobado por la Comisión en su 137 período ordinario de sesiones, celebrado del 28 de octubre al 13 de noviembre de 2009, y modificado 2 de septiembre de 2011,

${ }^{59}$ Sección 4. Procedimiento. Artículo 48.1. La Comisión, al recibir una petición o comunicación en la que se alegue la violación de cualquiera de los derechos que consagra esta Convención, procederá en los siguientes términos: a. si reconoce la admisibilidad de la petición o comunicación solicitará informaciones al Gobierno del Estado al cual pertenezca la autoridad señalada como responsable de la violación alegada, transcribiendo las partes pertinentes de la petición o comunicación. Dichas informaciones deben ser enviadas dentro de un plazo razonable, fijado por la Comisión al considerar las circunstancias de cada caso; b. recibidas las informaciones o transcurrido el plazo fijado sin que sean recibidas, verificará si existen o subsisten los motivos de la petición o comunicación. De no existir o subsistir, mandará archivar el expediente; c. podrá también declarar la inadmisibilidad o la improcedencia de la petición o comunicación, sobre la base de una información o prueba de sobrevinientes; d. si el expediente no se ha archivado y con el fin de comprobar los hechos, la Comisión realizará, con conocimiento de las partes, un examen del asunto planteado en la petición o comunicación. Si fuere necesario y conveniente, la Comisión realizará una investigación para cuyo eficaz cumplimiento solicitará, y los Estados interesados las proporcionarán, todas las facilidades necesarias; e. podrá pedir a los Estados interesados cualquier información pertinente, y recibirá, si así se le solicita, las exposiciones verbales o escritas que presenten los interesados; f. se pondrá a disposición de las partes interesadas, a fin de llegar a una solución amistosa del asunto fundada en el respeto a los derechos humanos reconocidos en esta Convención. 2. Sin embargo, en casos graves y urgentes, puede realizarse una investigación previo consentimiento del Estado en cuyo territorio se alegue haberse cometido la violación, tan solo con la presentación de una petición o comunicación que reúna todos los requisitos formales de admisibilidad.

${ }^{60} \mathrm{Si} \mathrm{se} \mathrm{hallegado} \mathrm{a} \mathrm{una} \mathrm{solución} \mathrm{amistosa} \mathrm{con} \mathrm{arreglo} \mathrm{a} \mathrm{las} \mathrm{disposiciones} \mathrm{del} \mathrm{inciso} \mathrm{1.f.} \mathrm{del} \mathrm{artículo} \mathrm{48,} \mathrm{la} \mathrm{Comisión} \mathrm{redactará}$ un informe que será transmitido al peticionario y a los Estados partes en esta Convención y comunicado después, para su publicación, al Secretario General de la Organización de los Estados Americanos. Este informe contendrá una breve exposición de los hechos y de la solución lograda. Si cualquiera de las partes en el caso lo solicitan, se les suministrará la más amplia información posible (artículo 49).

${ }^{61}$ De no llegarse a una solución, y dentro del plazo que fije el Estatuto de la Comisión, esta redactará un informe en el que expondrá los hechos y sus conclusiones. Si el informe no representa, en todo o en parte, la opinión unánime de los miembros de la Comisión, cualquiera de ellos podrá agregar a dicho informe su opinión por separado. También se agregarán al informe las exposiciones verbales o escritas que hayan hecho los interesados en virtud del inciso 1.e. del artículo 48. El informe será transmitido a los Estados interesados, quienes no estarán facultados para publicarlo. 3. Al transmitir el informe, la Comisión puede formular las proposiciones y recomendaciones que juzgue adecuadas. Artículo 50.

${ }^{62}$ La solución amistosa. La Comisión se pondrá a disposición de las partes en cualquier etapa del examen de una petición o caso, por iniciativa propia o a solicitud de cualquiera de ellas, a fin de llegar a una solución amistosa del asunto fundada en el respeto de los derechos humanos establecidos en la Convención Americana sobre Derechos Humanos, la Declaración Americana y otros instrumentos aplicables. El procedimiento de solución amistosa se iniciará y continuará con baseen el consentimiento delas partes. Cuandoloconsiderenecesario, la Comisión podráencomendar aunoo más de sus miembros la tarea de facilitar la negociación entre las partes. La Comisión podrá dar por concluida su intervención en el procedimiento de solución amistosa si advierte que el asunto no es susceptible de resolverse por esta vía, o alguna de las partes consiente en su aplicación, decide no continuar en él, o no muestra la voluntad de llegar a una solución amistosa fundada en el respeto de los derechos humanos. 5. Si se logra una solución amistosa, la Comisión aprobará un informe con una breve exposición de los hechos y de la solución lograda, lo transmitirá a las partes y lo publicará. Antes de aprobar dicho informe, la Comisión verificará si la víctima de la presunta violación o, en su caso, sus derechohabientes, han dado su consentimiento en el acuerdo de solución amistosa. En todos los casos, la solución amistosa deberá fundarse en el respeto de los derechos humanos reconocidos en la Convención Americana sobre Derechos Humanos, la Declaración Americana y otros instrumentos aplicables. 6. De no llegarse a una solución amistosa, la Comisión proseguirá con el trámite de la petición o caso. 
como también en el Reglamento de la Corte en su artículo $63,{ }^{63}$ aprobado por la Corte en su LXXXV Período Ordinario de Sesiones celebrado del 16 al 28 de noviembre de2009. Como hemos podido observar, la solución amistosa es un procedimiento dentro del ámbito del Derecho Internacional que puede permitir el fin del reclamo, sin que medie sentencia del Tribunal o dictamen del amicus curiae o mediador. Aun cuando su fundamento se encuentra en la voluntad de las partes, se halla limitado por la necesidad de ausencia de todo tipo de coacción o violencia de una hacia la otra; de lo que especialmente se trata es de limitar el rol del Estado y sujetar el acuerdo final a la homologación del Tribunal Internacional. ${ }^{64}$ Es siempre conveniente dar conocimiento tanto a la Comisión (o su delegado para el caso) como a la Corte de las gestiones que se están llevando a cabo y de los plazos que se manejan. Esto es no solo recomendable a los representantes de las víctimas sino también al Estado, ya que le da mayor transparencia a la gestión, que aún entablada no implica resultado positivo. El Derecho Internacional se encuentra enriquecido por dos fenómenos que van a coincidir luego en la forma de solución de controversias. La Comisión deberá ser el pilar de las negociaciones, en especial el miembro designado por esta, ya que es quien posee los mayores conocimientos de los logros y desaciertos de las negociaciones iniciales, como asítambién las pretensiones de los demandantes y la voluntad de solución del Estado o de sus representantes y las dificultades a nivel nacional para cumplir conlos objetivos propuestos. En ese sentido, la Comisión cumple un rol de mediador, desplegandotres funciones principales: 1) Acercaralas partes, 2) Coadyuvar en la búsqueda de una solución satisfactoria, y 3) Lograr que el órgano competente homologue el acuerdo. Con la apertura del caso, la Comisión fijará un plazo de tres meses para que los peticionarios presenten sus observaciones adicionales sobreel fondo. Las partes pertinentes de dichas observaciones serán transmitidas al Estado en cuestión a fin de que presente sus observaciones dentro del plazo de tres meses. La Secretaría Ejecutiva evaluará solicitudes de prórroga de los plazos mencionados en el inciso precedente que estén debidamente fundadas. En caso de gravedad y urgencia o cuando se considere que la vida de una persona o su integridad personal se encuentre en peligro real e inminente y una vez abierto el caso, la Comisión solicitará al Estado que envíe sus observaciones adicionales sobre el fondo dentro de un plazo razonable, fijado por la Comisión al considerar las circunstancias de cada caso. Antes de pronunciarse sobre el fondo de la petición, la Comisión fijará un plazo para que las partes manifiesten si tienen interés en iniciar el procedimiento de solución amistosa previsto en el artículo 40 del presente Reglamento.

${ }^{63}$ Artículo 63. Solución amistosa. Cuando la Comisión, las víctimas o presuntas víctimas o sus representantes, el Estado demandando y, en su caso, el Estado demandante, en un caso ante la Corte comunicaren a esta la existencia de una solución amistosa, de un avenimiento o de otro hecho idóneo para la solución del litigio, la Corte resolverá en el momento procesal oportuno sobre su procedencia y sus efectos jurídicos.

${ }^{64}$ Jorge Nelson Cardoso. "La Solución Amistosa ante la Corte”. En El Futuro del Sistema Interamericano de Protección de los Derechos Humanos, ed. Juan E. Méndez y Francisco Cox, $1^{\text {a }}$. ed. San José: Instituto Interamericano de Derechos Humanos, 1998, p. 395. 


\section{DECISIÓN E INFORME SOBRE EL FONDO}

La Comisión deliberará sobre el fondo del caso, a cuyo efecto preparará un informe en el cual examinará los alegatos, las pruebas suministradas por las partes y la información obtenida durante audiencias y observaciones in loco. Asimismo, la Comisión podrá tener en cuenta otra información de público conocimiento. Las deliberaciones de la Comisión se harán en privado y todos los aspectos del debate serán confidenciales; toda cuestión que deba ser puesta a votación se formulará en términos precisos en uno de los idiomas de trabajo de la Comisión. Si el informe no representa, en todo o en parte, la opinión unánime de los miembros de la Comisión, cualquiera de ellos podrá agregar su opinión por separado siguiendo el procedimiento establecido en el artículo 19 inciso 4 del presente Reglamento. ${ }^{65}$ Luego de la deliberación y voto sobre el fondo del caso, la Comisión procederá de la siguiente manera: ${ }^{66} 1$ ) Si establece que no hubo violación en un caso determinado, así lo manifestará en su informe sobre el fondo. El informe serátransmitido a las partes, y serápublicadoe incluido en el Informe Anual de la Comisión a la Asamblea General de la OEA; 2) Si establece una o más violaciones, preparará un informe preliminar con las proposiciones y recomendaciones que juzgue pertinentes y lo transmitirá al Estado en cuestión. En tal caso, fijará un plazo dentro del cual el Estado en cuestión deberá informar sobre las medidas adoptadas para cumplir las recomendaciones; 3) El Estado no estará facultado para publicar el informe hasta que la Comisión adopte una decisión al respecto; 4) Notificará al peticionario la adopción del informe y su transmisión al Estado. En el caso de los Estados parte en la Convención Americana que hubieran aceptado la jurisdicción contenciosa de la Corte Interamericana, al notificar al peticionario la Comisión dará a este la oportunidad de presentar, dentro del plazo de un mes, su posición respecto del sometimiento del caso a la Corte. Si el peticionario tuviera interés en que el caso sea sometido a la Corte, deberá presentar los siguientes elementos: 1)La posición de la víctima o sus familiares, si fueran distintos del peticionario; 2) Los datos de la víctimay sus familiares; 3 )Los fundamentos con baseenlos cuales consideraque elcaso debe ser remitido a la Corte; y 4) Las pretensiones en materia de reparaciones y costas.

\section{PUBLICACIÓN DEL INFORME}

El informe definitivo será transmitido a las partes, quienes presentarán, en el plazo fijado por la Comisión Interamericana de Derechos Humanos, información sobre el cumplimiento delas recomendaciones. LaComisión evaluaráel cumplimientode sus recomendaciones con base enlainformación disponible, y decidirá, por mayoría absoluta de votos de sus miembros, sobre la publicación del informe definitivo. La Comisión decidirá asimismo sobre su inclusión

\footnotetext{
${ }^{65}$ Artículo 43 del Reglamento de la Comisión Interamericana de Derechos Humanos.

${ }^{66}$ Artículo 44 del Reglamento de la Comisión Interamericana de Derechos Humanos, aprobado por la Comisión en su 137 Período ordinario de Sesiones, celebrado del 28 de octubre al 13 de noviembre de 2009, y modificado el 2 de septiembre de 2011.
} 
enelInforme AnualalaAsamblea General delaOEA osupublicación encualquierotromedio que considere apropiado. ${ }^{67}$ Una vez publicado un informe sobre solución amistosa o sobre el fondo en el que haya formulado recomendaciones, la Comisión podrá tomar las medidas de seguimiento que considere oportunas, tales como solicitar información a las partes y celebrar audiencias, con el fin de verificar el cumplimiento de los acuerdos de solución amistosa y recomendaciones. La Comisión informará de la manera que considere pertinente sobre los avances en el cumplimiento de dichos acuerdos y recomendaciones. ${ }^{6}$ Los originales de los informes firmados por los Comisionados que participaron en su adopción serán depositados en los archivos de la Comisión. Los informes transmitidos a las partes serán certificados por la Secretaría Ejecutiva. ${ }^{69}$ La comunicación presentada por un Estado parte en la Convención Americana, que ha aceptado la competencia de la Comisión para recibir y examinar tales comunicaciones contra otros Estados partes, será transmitida al Estado parte aludido, sea que este haya aceptado o no la competencia de la Comisión. En caso de no haberla aceptado, la comunicación será transmitida a los efectos de que dicho Estado pueda ejercer su opción bajo el artículo 45, párrafo 3, de la Convención, para reconocer esa competencia en el caso específico objeto de la comunicación. Aceptada la competencia por el Estado aludido para conocer de la comunicación del otro Estado parte, el respectivo trámite se regirá por las disposiciones de este Capítulo II, en lo que le sean aplicables. ${ }^{70}$

\section{LA REMISIÓN DE LOS CASOS A LA CORTE INTERAMERICANA DE DERECHOS HUMANOS (CDH)}

Si el Estado en cuestión ha aceptado la jurisdicción de la Corte Interamericana, de conformidad con el artículo 62 de la Convención Americana, y la Comisión considera que no ha cumplido las recomendaciones del informe aprobado de acuerdo al artículo 50 del referido instrumento, someterá el caso a la Corte Interamericana de Derechos Humanos, salvo por decisión fundada de la mayoría absoluta de los miembros de la Comisión. La Comisión considerará fundamentalmente la obtención de justicia en el caso particular, fundada entre otros, en los siguientes elementos: ${ }^{71} 1$ ) La posición del peticionario, 2) La naturaleza y gravedad de la violación, 3) La necesidad de desarrollar o aclarar la jurisprudencia del sistema, y 4) El

${ }^{67}$ Artículo 47 del Reglamento de la Comisión Interamericana de Derechos Humanos, aprobado por la Comisión en su 137 Período Ordinario de Sesiones, celebrado del 28 de octubre al 13 de noviembre de 2009, y modificado el 2 de septiembre de 2011.

${ }^{68}$ Artículo 48 del Reglamento de la Comisión Interamericana de Derechos Humanos, aprobado por la Comisión en su 137 Período ordinario de Sesiones, celebrado del 28 de octubre al 13 de noviembre de 2009, y modificado el 2 de septiembre de 2011.

${ }^{69}$ Artículo 49 del Reglamento de la Comisión Interamericana de Derechos Humanos.

${ }^{70}$ Artículo 50 del Reglamento de la Comisión Interamericana de Derechos Humanos.

${ }^{71}$ Artículo 45 del Reglamento de la Comisión Interamericana de Derechos Humanos, aprobado por la Comisión en su 137 Período Ordinario de Sesiones, celebrado del 28 de octubre al 13 de noviembre de 2009, y modificado el 2 de septiembre de 2011. 
eventual efecto de la decisión en los ordenamientos jurídicos de los Estados miembros. Cuando la Comisión, de conformidad con el artículo 61 de la Convención Americana sobre Derechos Humanos y el artículo 45 del presente Reglamento, decida someter un caso a la jurisdicción contenciosa de la Corte Interamericana, remitirá al Tribunal, a través de su Secretaría, copia del informe previsto en el Artículo 50 de la Convención Americana acompañado de copia del expediente en trámite ante la Comisión, con exclusión de los documentos de trabajo interno, más cualquier otro documento que considere útil para el conocimiento del caso. La Comisión remitirá asimismo una nota de envío del caso a la Corte, la cual podrá contener: 1) Los datos disponibles de las víctimas o sus representantes debidamente acreditados, con la indicación de si el peticionario ha solicitado reserva de identidad; 2) Su evaluación sobre el grado de cumplimiento de las recomendaciones formuladas en el informe de fondo; 3) El motivo por el cual se decidió someter el caso a la Corte; 4) Los nombres de sus delegados; y 5) Cualquier otra información que considere útil para el conocimiento del caso. Una vez sometido el caso a la jurisdicción de la Corte, la Comisión hará público el informe aprobado conforme al artículo 50 de la Convención Americana y la nota de envío del caso a la Corte. ${ }^{72} \mathrm{La}$ Comisión remitirá a la Corte, a solicitud de esta, cualquier otra petición, prueba, documento o información relativa al caso, con la excepción de los documentos referentes a la tentativa infructuosa de lograr una solución amistosa. La transmisión de los documentos estará sujeta, en cada caso, a la decisión de la Comisión, la que deberá excluir el nombre e identidad del peticionario, si este no autorizara la revelación de estos datos. ${ }^{73}$

\section{SUSPENSIÓN DEL PLAZO PARA EL SOMETIMIENTO DEL CASO A LA CORTE $^{74}$}

La Comisión podrá considerar a solicitud del Estado interesado la suspensión del plazo previsto en el artículo 51.1. de la Convención Americana para el sometimiento del "Caso" a la Corte, cuando estuvieren reunidas las siguientes condiciones: 1) Que el Estado haya demostrado su voluntad de implementar las recomendaciones contenidas en el informe sobre elfondo, mediante la adopción de acciones concretas e idóneas orientadas a su cumplimiento; y 2) Que en su solicitud el Estado acepte en forma expresa e irrevocable la suspensión del plazo previsto en el artículo 51.1. de la Convención Americana para el sometimiento del caso a la Corte y, en consecuencia, renuncie expresamente a interponer excepciones preliminares respecto del cumplimiento con dicho plazo, en la eventualidad de que el asunto sea remitido a la Corte.

\footnotetext{
${ }^{72}$ Artículo 74 del Reglamento de la Comisión Interamericana de Derechos Humanos, aprobado por la Comisión en su 137 Período Ordinario de Sesiones, celebrado del 28 de octubre al 13 de noviembre de 2009, y modificado el 2 de septiembre de 2011.

${ }^{73}$ Artículo 76 del Reglamento de la Comisión Interamericana de Derechos Humanos.

${ }^{74}$ Artículo 46 del Reglamento de la Comisión Interamericana de Derechos Humanos.
} 


\section{CONCLUSIÓN}

Cerramos este artículo con una conclusión general: que la Comisión Interamericana de Derechos Humanos es un órgano principal y fundamental del Sistema Interamericano de Derechos Humanos, reconocimiento que le han otorgado los Estados al firmar y ratificar la Convención Americana de Derechos Humanos en su artículo 33, razón por la cual todas las recomendaciones que dé esteórgano de promoción y defensa de los derechos humanos deben ser implementadas y cumplidas en los plazos previstos, máxime si se tiene en cuenta que el no implementarlas llevaráque esos casos sean sometidos a la Corte Interamericana de Derechos Humanos. En ese sentido, dar la imagen de no querer cumplir los mandatos de la Comisión para discutir en el contencioso judicial supranacional se presentaría como un desconocimiento puro del Sistema Interamericano, o como muestra de vanidad improvisada, sobre todo si se observa que hay casos que nacen perdidos por la clara violación de los derechos humanos en el marco de la vigencia y cumplimiento de la Convención Americana de Derechos Humanos y otros tratados universales. 


\section{REFERENCIAS}

- Cardoso, Jorge Nelson. "La Solución Amistosa ante la Corte". En El Futuro del Sistema Interamericano de Protección de los Derechos Humanos, ed. Juan E. Méndez y Francisco Cox, $1^{\text {a }}$. ed. San José: Instituto Interamericano de Derechos Humanos, 1998.

- Méndez, JuanE. “Una aproximación crítica a la interpretación vigente de los artículos 50y 59 dela Convención". En ElFuturo del Sistema Interamericano de Protección de los Derechos Humanos, ed. Juan E. Méndez y Francisco Cox, $1^{\text {a }}$. ed. San José: Instituto Interamericano de Derechos Humanos, 1998.

- Nikken, Pedro. "Perfeccionar el sistema interamericano de derechos humanos sin reformar al Pacto de San José”. En El futuro del Sistema Interamericano de Protección de los Derechos Humanos, ed. Juan E. Méndez y Francisco Cox, $1^{\text {a }}$. ed. San José: Instituto Interamericano de Derechos Humanos, 1998. pp. 25-41.

- Quiroga, Cecilia Medina y Claudio Nash Rojas. Sistema Interamericano de Derechos Humanos: introducción a sus mecanismos de protección. Chile: Facultad de Derecho de la Universidad de Chile, 2007. 


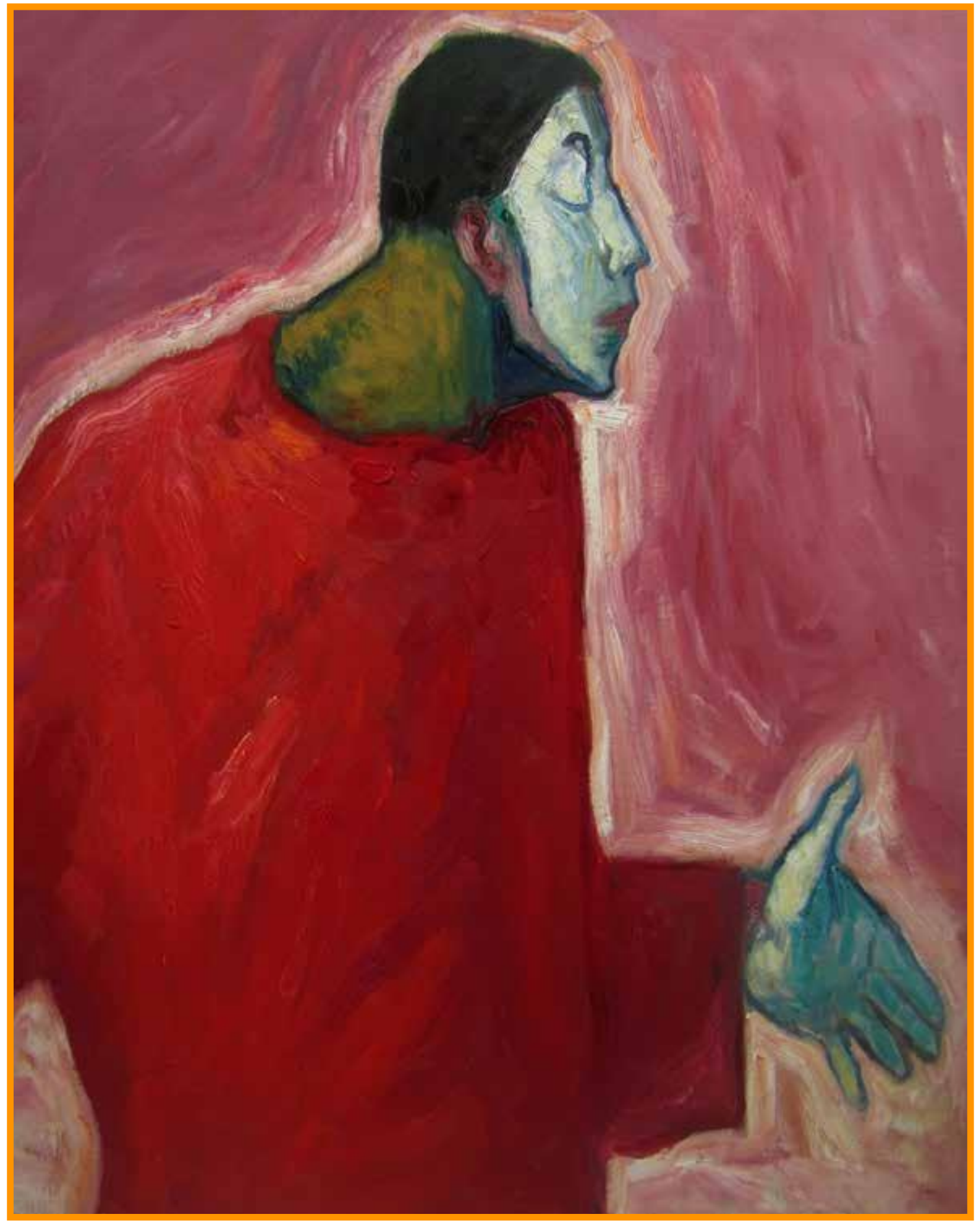

Mimo actuando. Óleo sobre tela $(100$ x $81 \mathrm{~cm})$. 